\title{
IDAS: una metodología de enseñanza centrada en el estudiante para favorecer el aprendizaje de la física
}

IDAS: a student-centered teaching methodology to encourage the learning of physics

\author{
Bettina Bravo*1@, Marta Pesa² ${ }^{2}$ Mariné Braunmüller ${ }^{3}$ \\ ${ }^{1}$ CONICET - Universidad Nacional del Centro de la Provincia de Buenos Aires, Facultad de Ingeniería, Buenos Aires, \\ Argentina. \\ ${ }^{2}$ Universidad Tecnológica Nacional, Facultad Regional Tucumán, San Miguel de Tucumán, Argentina. \\ ${ }^{3}$ Universidad Nacional del Centro de la Provincia de Buenos Aires, Facultad de Ingeniería, Buenos Aires, Argentina.
}

Recibida en 11 de Septiembre, 2021. Revisado en 11 de Noviembre, 2021. Aceptado en 08 de Diciembre, 2021.

Los grandes y continuos desarrollos científico-tecnológicos que caracterizan a los tiempos actuales, sin duda han transformado la sociedad en que vivimos. Por ello, es un objetivo (y obligación) de la educación obligatoria favorecer una alfabetización científico - tecnológica de todos los estudiantes. Para lograr este objetivo, la educación no se puede limitar a la escuela, sino que diferentes sectores sociales deben promover espacios y propuestas de educación formal, no formal e informal que contribuyan a las prácticas del aula. Con esta premisa en mente, un grupo de profesores-investigadores universitarios, especialistas en docencia científica y tecnología educativa, trabajando bajo el paradigma de la investigación basada en el diseño, y de manera conjunta y colaborativa con profesores de física de secundaria, diseñamos la metodología de enseñanza IDAS (Iniciación, Desarrollo, Aplicación y Síntesis). IDAS es una metodología centrada en el estudiante y basada en el aprendizaje, que busca promover la comprensión de conceptos, leyes y teorías relacionadas con la ciencia, así como promover el desarrollo de habilidades relacionadas con la resolución de problemas y el uso crítico y estratégico de las tecnologías de la información y la comunicación. En este trabajo se presenta, describe, fundamenta y ejemplifica la metodología de enseñanza IDAS y se comparten algunos resultados obtenidos al implementarlo en el aula.

Palabras claves: Metodología de enseñanza, Aprendizaje activo, Física, Resolución de Problemas, TIC.

The continuous scientific-technological developments, which characterize the current times, have undoubtedly transformed the society we live in. Therefore, it is mandatory education's objective to promote scientific and technological literacy for all students. To attain this, education must not be limited to the school, but rather different social sectors must promote spaces and proposals for formal, non-formal and informal education that contribute to classroom practices. With this premise in mind, a group of university professor-researchers, specialists in scientific teaching and educational technology, taking the paradigm of design-based research and in cooperation with secondary school physics teachers, we have designed the teaching methodology IDAS (Initiation, Development, Application and Synthesis). IDAS is a student-centered and learning-based methodology that seeks to promote the understanding of concepts, laws and theories related to science. Simultaneously it promotes the development of skills related to problem solving and critical and strategic use of the technology of information and communication. In this work, the IDAS teaching methodology is presented, described, substantiated and exemplified. Some results obtained by implementing it in the classroom are shared.

Keywords: Teaching methodology, Active learning, Physics, Problem resolution, ICTs.

\section{Introducción}

Sin duda alguna el mundo contemporáneo se caracteriza por los grandes y continuos desarrollos científicotecnológicos que han transformado, rápida y vertiginosamente la sociedad en que vivimos. El derecho de los ciudadanos a no ser manipulados, a comprender los fenómenos que les afectan y a intervenir criteriosa y activamente en la conducción de los procesos sociales, requiere hoy de la adquisición de conocimientos científico tecnológico y el desarrollo de la habilidad de usarlo, con

\footnotetext{
* Correo electrónico: bbravo@fio.unicen.edu.ar
}

consistencia y coherencia argumentativa, como instrumento estratégico.

Desde esta perspectiva, la enseñanza formal de contenidos inherentes a las ciencias y la tecnología resulta indiscutiblemente necesaria. Se requieren también nuevas metodologías para abordarlos y nuevas propuestas para el desarrollo de habilidades científicas.

En concordancia con ello las reformas educativas implementadas en los últimos años en Argentina, en sintonía con la tendencia mundial, han abordado a la alfabetización científica como uno de los objetivos generales de la educación obligatoria (que se extiende desde los 4 a los 17 años de edad), alfabetización 
entendida como una estrategia orientada a lograr la apropiación de conocimientos y saberes acerca de la ciencia que permitan participar y fundamentar decisiones con respecto a temas científicos de impacto social [1]. Así también se prescribe como finalidad de la educación obligatoria el desarrollo de competencias digitales que les permitan a los sujetos utilizar de forma creativa, critica, segura y estratégica las Tecnologías de la Información y Comunicación (TIC) para buscar, obtener, procesar y comunicar información; transformarla en conocimiento y aplicarlo para tomar decisiones y resolver problemas en contextos variados.

La educación hoy se enfrenta al gran desafío de favorecer la alfabetización científico - tecnológica (digital) de los estudiantes. Entendemos que para lograr ese objetivo no podemos limitar la educación a la escuela, sino que desde distintos sectores sociales se deberían propiciar espacios y propuestas de educación formal, no formal e informal que contribuyan con las prácticas educativas escolares y que tengan la intencionalidad de favorecer la construcción de un saber y saber hacer coherente con el de la ciencia y las nuevas tecnologías. Afrontar este gran desafío, requiere de un trabajo cooperativo donde distintos actores del sistema educativo (pertenecientes a diferentes niveles y formaciones académicas) interpelen e interpreten desde sus conocimientos y experiencias la realidad áulica y el objetivo de la enseñanza de saberes específicos y planteen propuestas de enseñanza innovadoras potencialmente útiles para alcanzar esos objetivos.

Con esta premisa en mente un grupo de docentes investigadores universitarios especialistas en enseñanza científica y tecnología educativa, trabajando en forma conjunta y colaborativa con profesores de física de educación secundaria hemos diseñando, bajo el paradigma de investigación basada en diseño [2, una propuesta metodológica para la enseñanza de la Física en nivel secundario que llamamos IDAS (iniciales de las cuatro instancias didácticas involucradas en el método: Iniciación, Desarrollo, Aplicación e Síntesis) en distinción a las instancias didácticas que ésta contempla [3]. En términos generales, a IDAS se la podría definir como una propuesta de enseñanza (PE) basada en el aprendizaje con la que se busca favorecer la comprensión de conceptos, leyes y teorías relacionadas con las ciencias como así también propiciar el desarrollo de competencias relacionadas con la resolución de problemas y el uso crítico y estratégico de las TIC.

El objetivo de este trabajo es presentar, describir, fundamentar y ejemplificar la PE-IDAS, como así también compartir algunos primeros resultados obtenidos al implementarla en el aula.

Para ello comenzamos compartiendo qué entendemos por aprender ciencias y qué procesos están involucrados en ese aprendizaje para luego delimitar qué estrategias de enseñanza lo favorecería más eficazmente. La delimitación del modelo de aprendizaje, dará significado a la propuesta y sustentará las metodologías a usar en cada etapa.

\section{Sobre Qué Significa Aprender Ciencias}

La premisa central en la que se basa nuestro trabajo implica asumir que un individuo alfabetizado científicamente es aquel que conoce, interpreta, comprende el saber de la ciencia (y con ello el significado de los conceptos, los enunciados de las leyes, los postulados de las teorías que lo conforman) y es capaz de usarlo con conciencia, consistencia y coherencia argumentativa para resolver problemas significativos para él y el entorno social donde está inmerso. En relación a ello sostenemos que:

- para comprender el conocimiento científico el sujeto debe aprender a interpretar el mundo desde un punto de vista ontológica, epistemológica y conceptualmente más próximo y consistente con la ciencia. Dado que intuitivamente construimos conocimientos, interpretamos el mundo y abordamos y resolvemos problemas desde perspectivas radicalmente diferentes, aprender ciencia requerirá y conllevará un cambio de modo de conocer y modo de aprender.

- no basta comprender el saber de la ciencia para poder transferirlo y aplicarlo para resolver problemas. La tarea de resolución de problemas involucra además una serie de habilidades que el sujeto debe desarrollar; debe aprender a hacer.

- así como no corresponde separar el conocimiento del hacer, tampoco parece adecuado separar conocimiento y acciones de las valoraciones. El logro de un pensamiento crítico y reflexivo, el desarrollo de capacidades de trabajo cooperativo, de argumentación y justificación, requiere modificaciones progresivas y profundas en el modo de conocer.

En los siguientes apartados intentaremos justificar estas premisas.

\subsection{Aprender a (re) interpretar el mundo}

Desde pequeños, desde los primeros contactos que tenemos con el mundo y al interrogarnos permanentemente sobre su comportamiento, los sujetos construimos conocimientos (habitualmente llamados intuitivos) basándonos en los datos que nuestros sentidos nos proporcionan o los cambios que en nuestro organismo se producen cuando interaccionamos con el entorno.

Así, a partir de un aprendizaje implícito e inconsciente [4, 5], construimos el conocimiento necesario para hacer más predecible y controlable el mundo y poder actuar en él. Gracias a ese conocimiento somos capaces, por ejemplo, de predecir el movimiento de los automóviles para decidir si cruzamos o no una calle o decidir sobre la posición relativa fuente de luz - objeto - 
espejo si queremos ver nuestra imagen reflejada en él, sin que necesitemos hacer ningún calculo o acudir a un conocimiento formal.

A esa construcción del conocimiento intuitivo subyace implícitamente la premisa de que el mundo es tal y como aparece ante nuestros sentidos por lo que concebimos que nuestros conocimientos (construidos a partir de los datos aportados por dichos sentidos) reflejan fielmente la realidad. Así, basado en esa fe realista se asume una "transparencia representacional" del conocimiento [6, 7] desconociéndose la existencia de distintas maneras alternativas de interpretar y explicar los fenómenos que suceden.

Otra característica del aprendizaje que llevamos a cabo cuando nos enfrentamos a un dato/objeto/hecho/ fenómeno novedoso es que tendemos a asociarlo a una categoría ontológica previamente definida a la que atribuimos unas propiedades determinadas [8] 10. Entre esas grandes categorías se hallan la de materia y procesos. Así, si consideramos que algo es materia, en especial desde el modo de conocer intuitivo, le atribuimos ciertos atributos que les serían propios (ocupar un lugar en el espacio, tener masa, ser contenible o poder contener, por ejemplo) y le atribuimos una naturaleza ontológica objetiva suponiendo que se trata de un objeto existente en el mundo. En cambio, interpretar un fenómeno como proceso, característica del conocimiento científico, implica concebirlo como un hecho o un suceso, que se desarrolla en el tiempo, que puede tener diferente naturaleza, que involucra un sistema de componentes interactuantes.

$\mathrm{Al}$ respecto, desde el conocimiento intuitivo, se tiende a usar la idea de objeto material ordinario como referencia ontológica, lo que lleva a dotar de propiedades intrínsecas, no sólo a los objetos sino a muchos fenómenos que requieren ser interpretados como procesos [11, 12]. Así por ejemplo se concibe que conceptos como "peso, movimiento, color, fuerza, energía", son entidades materiales y se los tiende a sustancializar de forma que se les atribuyen las propiedades de la materia. A su vez, si se reconoce algún proceso, alguna interacción entre las variables que intervienen en un fenómeno, se suele recurrir a un esquema causal muy simple para explicar los acontecimientos, según el cual la relación entre la causa y el efecto es lineal y en un solo sentido [4].

Así, a partir del saber intuitivo, asumiendo implícitamente que el mundo es y se comporta como nuestros sentidos nos lo indican y fiel a la tendencia de sustancializar los fenómenos y explicarlos en términos de causalidades lineales simples (reconociendo sólo algunos de los elementos involucrados) se elaboran, frecuentemente, explicaciones diferentes a las que propone la ciencia.

Como para citar sólo un ejemplo, desde el saber intuitivo se concibe al color como una propiedad del objeto que vemos con nuestros ojos cuando lo miramos. Desde el contexto científico, en cambio, se lo concibe como un fenómeno de percepción visual que sucede como consecuencia de la interacción luz - materia (a partir de los fenómenos de absorción y reflexión o trasmisión difusa) y luz - sistema visual (donde se producen múltiples y complejos procesos físicos, químicos, neurológicos, cognitivos). A su vez, la explicación de los fenómenos físicos asociados a este fenómeno requiere usar distintos modelos para interpretar la naturaleza de la luz. En tal sentido para interpretar y explicar los fenómenos de absorción a la luz se la debe modelar como una onda electromagnética, en tanto para explicar la formación de la imagen retiniana basta con modelarla como un "rayo".

Estas diferencias, que se evidencian al momento de explicar la mayoría de los fenómenos naturales desde un saber intuitivo y uno científico, se debería a las diferencias en las características del propio proceso de construcción de conocimientos puesto en juego en uno y otro contexto y a los supuestos ontológicos, epistemológicos y conceptuales sobre los que se sustentan dichos aprendizajes.

En tal sentido, el conocimiento científico es una construcción social compleja y laboriosa, cuya construcción demanda de un aprendizaje explícito, consciente, deliberado, costoso e intencional [5]. Los principios epistemológicos que subyacen a esta construcción implican concebir al conocimiento como un conjunto de modelos y múltiples representaciones explícitas que requieren ser gestionadas y utilizadas en función de la naturaleza del fenómeno, contexto o problema a resolver. En tal sentido, desde la epistemología contemporánea se propone que los modelos y teorías científicos son una construcción social, que no son la realidad misma, sino una manera más de interpretar el mundo, una forma de hablar o contar las cosas que suceden. Ese conocimiento sería una representación provisoria, perfectible e idealizada de un fenómeno físico o sistema; un cierto sistema real se concibe como plausible de ser representado por más de un modelo, y la preferencia por uno de ellos estaría determinada por factores tales como los propósitos del estudio, el problema a resolver, las condiciones de precisión exigidas [13, 14].

Ontológicamente, desde el contexto científico los fenómenos no se explican y conciben en términos de estados o propiedades de la materia sino como procesos, como una sucesión o encadenamiento de hechos y partir de sistemas que abarcan conjuntos de relaciones complejas [10].

Finalmente, el saber científico interpreta a las propiedades de los cuerpos y los fenómenos como un sistema de relaciones de interacción, sistémicas y recíprocas y no lineales y unidireccionales como lo tiende a hacer desde el saber intuitivo [15].

En síntesis, el conocimiento intuitivo que los sujetos construimos como consecuencia de nuestra interacción con el mundo físico y social que nos rodea y a partir de aprendizajes implícitos e inconscientes, resulta ontológico, epistemológico y conceptualmente diferente al conocimiento científico cuya construcción involucra un 


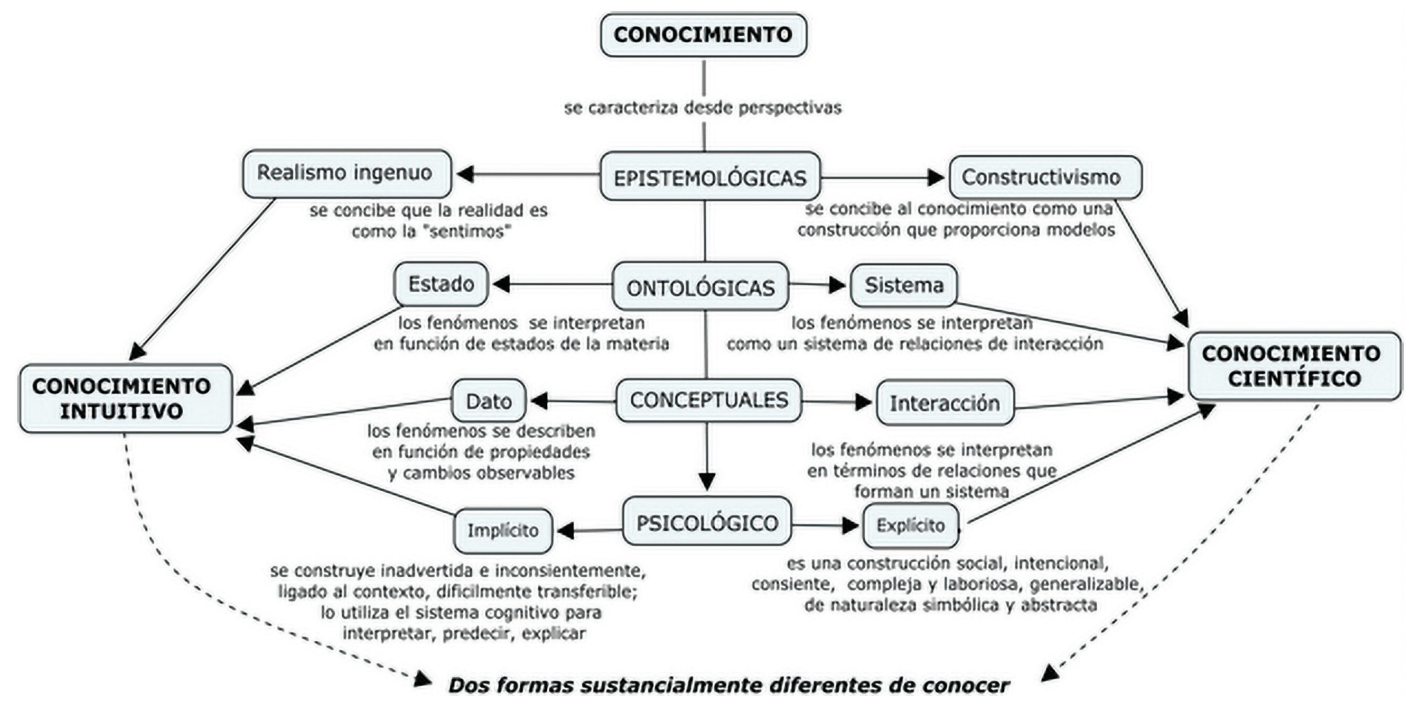

Figura 1: El saber intuitivo y el de las ciencias: dos formas sustancialmente diferentes de conocer.

aprendizaje explícito, intencional y consciente. En la Figura 1 se sintetizan las características de estas formas de conocer.

Estas diferencias que subyacen a cada forma de conocer, se manifiestan como distintos modos de razonamiento que se activan a la hora de resolver una situación problemática y elaborar una explicación, en un contexto cotidiano o uno científico. En tal sentido, a la hora de resolver problemas, desde el saber científico se despliegan destrezas como: generación de hipótesis, identificación y combinación de variables, construcción, elaboración y utilización coherente y consistente de modelos, recolección y transformación de datos, elaboración de conclusiones, entre otras. A su vez, la mayor parte de las teorías científicas requiere entender las situaciones como una interacción donde intervienen múltiples variables y complejos procesos, por lo que los modos de razonar activados son multivariados y sistémicos.

Desde el conocimiento intuitivo, en tanto, se tienden a usar modos de razonar espontáneos, que se diferencian de los de la ciencia por:

- ser monoconceptuales: en tanto los individuos simplifican acríticamente las situaciones problemáticas complejas y multivariadas, suponiendo a priori, que las respuestas dependen de una sola variable 16 propone justamente que nuestra comprensión intuitiva es demasiado simplista y que tendemos a basar nuestros juicios en el análisis de una sola variable por vez.

- estar basados en causalidades lineales: en tanto se tiende a la reducción funcional de los elementos en juego en la situación analizada ignorando los aspectos sistemáticos de los problemas. El razonamiento cotidiano, al contrario del científico, establece una sucesión lineal de relaciones de causa y efecto en la que cada uno de estos términos está asociado a una sola magnitud [11, 12.
- inconsistente: que implica el uso de dos o más significados diferentes para un mismo concepto sin ser conscientes de ello.

\subsection{Aprender ciencias: un profundo y paulatino cambio de modo de conocer}

A partir del análisis realizado en el punto anterior se puede concluir que aprender ciencias involucra una manera cualitativamente distinta a la cotidiana de aprender en tanto requiere de un aprendizaje explícito, más próximo a una concepción perspectivista del conocimiento, y una interpretación del mundo guiada por principios ontológicos de sistema, principios epistemológicos más cercanos al constructivismo y conceptuales que atiendan a la complejidad de las interacciones y superen el apego centrado en los datos, típico de un realismo ingenuo. A su vez ese aprendizaje, supone la adquisición de razonamientos sistémicos y la paulatina superación de razonamientos lineales, unidireccionales, no sistémicos, reduccionistas o puramente algorítmicos.

Aprender ciencias, y con ello comprender los conceptos, leyes, modelos que conforman su cuerpo de conocimiento, implica aprender a aprender de una forma diferente a la que lo hacemos naturalmente, como así también cambiar los supuestos sobre los que solemos basarnos al aprender sobre el mundo que nos rodea. En tal sentido, el aprendizaje de las conceptualizaciones científicas tiene asociado un cambio profundo en las estructuras conceptuales utilizadas por los sujetos en un dominio de conocimiento, desde las relaciones lineales y unidireccionales hasta las relaciones sistémicas y recíprocas como así también la creación de nuevas categorías ontológicas, una sofisticación epistemológica, y la reorganización de las estructuras cognitivas [7.

Este tipo de aprendizaje "involucra aprendizaje explícito, esforzado, consciente, que solo se produce de 
modo deliberado y con intención, que implica tomar conciencia de lo que ya somos implícitamente para así poder cambiar hábitos muy arraigados y modificar lo que ya está escrito en nuestras mentes sin que muchas veces nosotros lo sepamos" [5].

Resultados de investigaciones muestran que es posible favorecer con la enseñanza formal este tipo de aprendizaje, pero también dejan en evidencia que éste es un proceso complejo y lento durante el cual el modo de conocer inicial de quien aprende se va complejizando paulatinamente [3]. Esto es, de considerarse los fenómenos en función de estados/características de la materia, reconociéndose parcialmente las variables involucradas y desconociéndose las relaciones e interacciones entre ellas (lo que implica un modo de razonar mono variado, reduccionista, construido en base a una fe realista); se suele pasar a reconocer mayor número de variables, concibiéndoselas relacionadas a partir de ciertos procesos que son explicados en términos de causalidades lineales considerándose que los modelos de la ciencia permiten esclarecer e interpretar esas relaciones. Finalmente, y usando esos estadios "intermedios" como plataforma, frecuentemente se llega a interpretar y explicar los fenómenos en término de sistemas e interacciones, de manera coherente con lo propuesto por la ciencia. En la Figura 2 se esquematiza el proceso descrito.

Pero estos cambios de modo de conocer no implican en ningún caso el abandono de las ideas intuitivas ni su sustitución por otras más complejas y cercanas a los propuestos por las de las ciencias, sino que conllevan la coexistencia de diversas representaciones en la mente de quien aprende [17]. Como propone Pozo [5]: "aprender no es escribir en una pizarra en blanco, pero tampoco es borrar lo que ya está escrito para sobrescribir encima". Las representaciones originales (aquellas de naturaleza implícita y procedimental), seguirán en la mente del sujeto junto a otras de naturaleza más explícitas (asequibles a la conciencia y verbalizarles) que va construyendo mientras aprende formalmente [18. Es decir, aunque los conocimientos científicos construidos durante el aprendizaje tengan mayor capacidad de transferencia a nuevos contextos, los

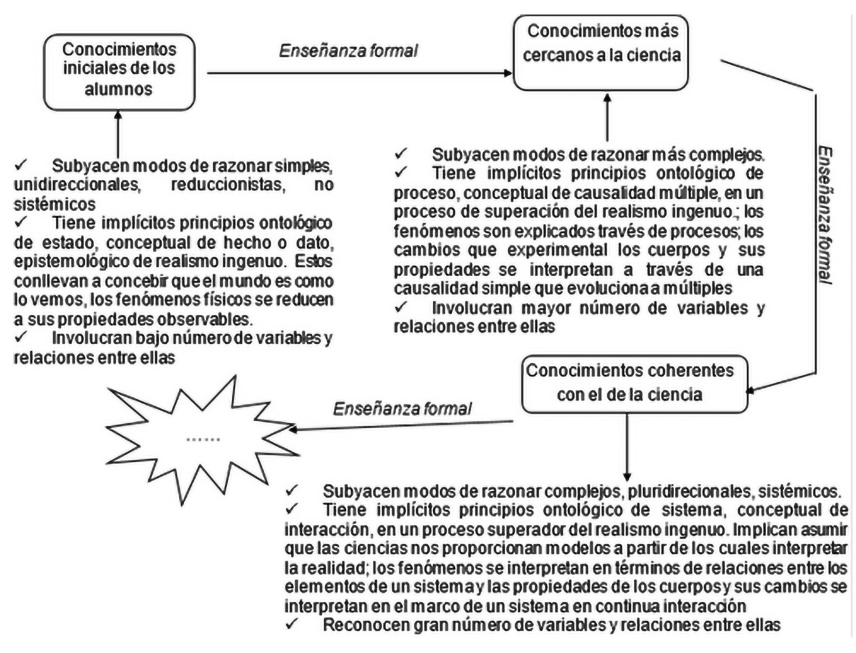

Figura 2: Evolución de los modos de conocer mediante la enseñanza, adoptado de [3].

conocimientos intuitivitos implícitos seguirán teniendo una función cognitiva sobre todo ante situaciones sobreaprendidas, por su funcionalidad pragmática.

Aprender ciencias implicará entonces adquirir la habilidad cognitiva para discriminar entre distintas representaciones a utilizar en función de la demanda del contexto implicado y aprender a hacer uso consciente, consistente y coherente de las mismas. En la Figura 3 se representan las características del aprendizaje hasta aquí desarrolladas.

\subsection{Aprender a resolver problemas}

Como ya se señaló, hoy más que nunca los conocimientos científicos deben servir a quien aprende para actuar criteriosamente y transformar la sociedad actual, caracterizada por rápidos y vertiginosos avances científicotecnológicos. Desde esta perspectiva, aprender el saber de las ciencias no sólo implicará interpretar los conceptos, leyes, modelos y teorías, sino también aprender a aplicarlas con coherencia para resolver problemas socialmente relevantes del entorno cotidiano y tomar decisiones responsables.

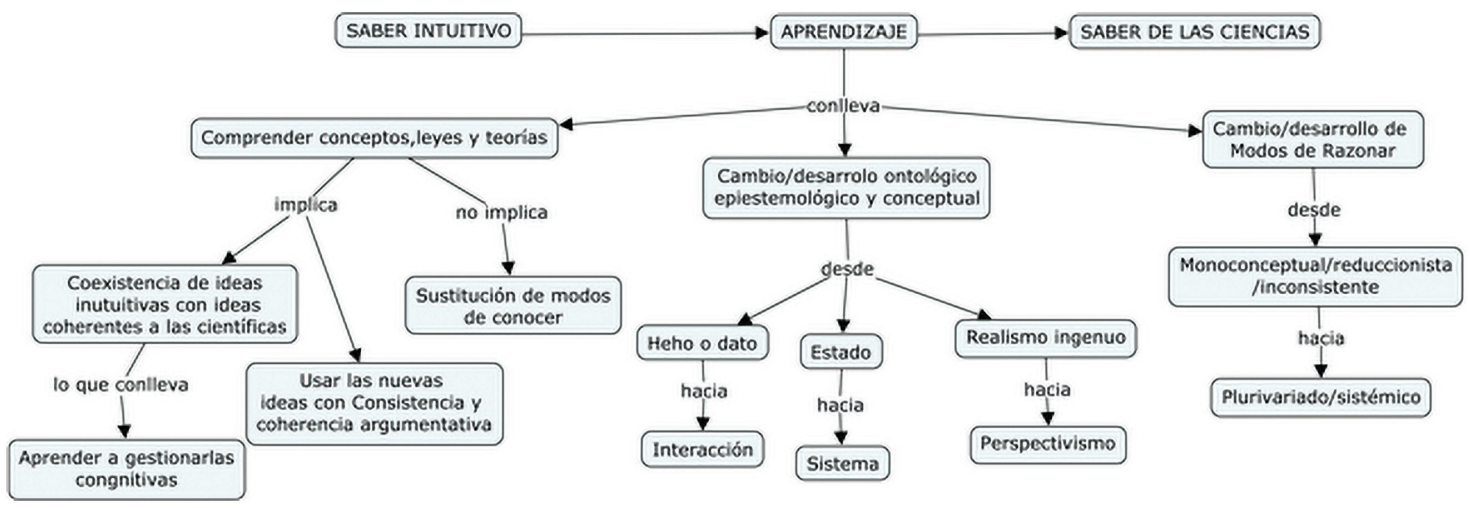

Figura 3: El aprendizaje de las ciencias. 
Pero entendemos que no hay una relación directa y automática entre conceptualizar el saber de la ciencia y saber aplicarlo para resolver problemas. La resolución de problemas implica en sí mismo un arduo aprendizaje y requiere de una enseñanza formal, explícitamente centrada en el desarrollo de estas competencias, con metodologías y estrategias intencionalmente diseñadas [19].

Tal como se sintetizan en el Cuadro 1. resolver problemas implicará, además de hacer uso de los conocimientos conceptuales, hacer uso de conocimientos procedimentales (como acotar el problema, formular hipótesis, diseñar y contrastar hipótesis a través de experimentos) y aplicar procesos tanto cognitivos (como analizar, identificar, comparar, clasificar, resumir, representar, relacionar variables, establecer analogías, elaborar conclusiones, argumentar sobre la validez de las conclusiones, evaluar) como metacognitivos (reflexión crítica sobre los propios procesos de planificación, desarrollo, evaluación, síntesis y la capacidad de retroalimentar, controlar y regular) [20, 22$]$

Cuadro 1: Etapas y estrategias implicadas en la resolución de problemas.

\begin{tabular}{|l|l|}
\hline Etapas & Ejemplo de estrategias asociadas \\
\hline $\begin{array}{l}\text { Interpretación } \\
\text { e }\end{array}$ & $\begin{array}{l}\text { Identificar el objetivo de la tarea; } \\
\text { incluir el problema en una categoría } \\
\text { del problema. } \\
\text { teórica; establecer relaciones entre los } \\
\text { elementos involucrados y representarlas } \\
\text { (de forma esquemática, coloquial y } \\
\text { usando el lenguaje matemático); } \\
\text { extraer información del enunciado } \\
\text { (detectar datos explícitos e implícitos, } \\
\text { reconocer los que resultan pertinentes } \\
\text { para la resolución y los que faltan, } \\
\text { identificar incógnitas). }\end{array}$ \\
\hline $\begin{array}{l}\text { Planificación y } \\
\text { ejecución de } \\
\text { un plan a } \\
\text { seguir para } \\
\text { resolver el } \\
\text { problema. }\end{array}$ & $\begin{array}{l}\text { modelo teórico más adecuado; } \\
\text { organizar los datos; buscar, seleccionar } \\
\text { y procesar la información necesaria; } \\
\text { seleccionar el método de resolución } \\
\text { más adecuado y seguir la secuencia de } \\
\text { resolución planificada. }\end{array}$ \\
\hline $\begin{array}{l}\text { Análisis de } \\
\text { datos y } \\
\text { Evaluación de } \\
\text { resultados y } \\
\text { acciones. }\end{array}$ & $\begin{array}{l}\text { Analizar datos y evaluar resultados } \\
\text { (a la luz de las predicciones y marco } \\
\text { teórico), el camino seguido y los logros } \\
\text { obtenidos. }\end{array}$ \\
\hline $\begin{array}{l}\text { Comunicación } \\
\text { de }\end{array}$ & $\begin{array}{l}\text { Comunicar resultados en forma verbal, } \\
\text { oral o escrita usando un lenguaje } \\
\text { apropiado. }\end{array}$ \\
\hline
\end{tabular}

Por lo expuesto, la resolución de problemas debe ser incluida, indudablemente, como objeto de enseñanza de las ciencias y no sólo como medio para aprender.

\subsection{Aprender con las TIC como aliadas}

Otro aspecto imposible de desatender al momento de intentar interpretar y caracterizar el aprendizaje de las ciencias en los tiempos que corren, es el impacto que han tenido (y tienen) las tecnologías de la información y la comunicación (TIC) en el estilo de vida, el trabajo, los pasatiempos, las relaciones sociales y hasta la manera de procesar la información por parte de los ciudadanos y ciudadanas.

La inclusión social y uso de las TIC están produciendo, "además de una profunda revolución tecnológica, comparable a las suscitadas por la escritura, la imprenta o la industrialización, el desarrollo de nuevas capacidades cognitivas" 23]. Como propone Lévy [24] "el ciberespacio soporta tecnologías intelectuales que amplifican, exteriorizan y modifican numerosas funciones primitivas humanas: memoria, imaginación, percepción y razonamientos".

Estas tecnologías favorecen y demandan nuevas formas de razonamiento y conocimiento que todas las personas han de adquirir y que la enseñanza formal debería ayudar a desarrollar. En consonancia con ello, la educación obligatoria está comenzando a plantearse como meta, el desarrollo de competencias digitales que permita a los jóvenes estudiantes convertirse en ciudadanos científica y también tecnológicamente cultos, capaces de insertarse, actuar criteriosamente, transformar la sociedad actual.

Pero, a su vez, la tecnología informática en las clases de Física se presenta como un instrumento facilitador para la interpretación de fenómenos físicos y la comprensión de los conceptos científicos involucrados [2528. De hecho, los recursos digitales pueden convertirse en potentes recursos didácticos en la enseñanza de las ciencias dada su potencialidad para simular fenómenos naturales difíciles de observar en la realidad, representar modelos de sistemas físicos inaccesibles, registrar procedimientos experimentales, facilitar la organización y tratamiento de datos, propiciar distintos medios para comunicar ideas y resultados, entre otras. En el Cuadro2 se enumeran algunos recursos digitales que pueden incluirse en las clases de ciencias, resaltándose su aptitud para favorecer el aprendizaje de contenidos, procedimientos y actitudes relacionadas con la ciencia en general y con esta disciplina en particular.

Por ello hoy no puede desconocerse a las TIC como aliadas; aliadas al aprender, por su potencialidad de convertirse en verdaderas prótesis cognitivas que amplíen y modifiquen nuestras capacidades mentales y de aprendizaje [5] y para la enseñanza (por su potencialidad como recurso didáctico).

\subsection{A modo de síntesis}

Aprender ciencias implicará para quien aprende:

- Complejizar, ontológica, epistemológica y conceptualmente sus modos intuitivos de conocer, tal que le permita interpretar los conceptos, leyes, teorías que conforman el saber de la ciencia, reconociéndolo como uno alternativo al "suyo" pero potencialmente útil para interpretar y actuar en el mundo actual. Esto implicará: 
Cuadro 2: Ejemplos de recursos digitales que pueden incluirse en las clases de ciencias.

\begin{tabular}{|c|c|c|}
\hline $\begin{array}{l}\text { Función a desarrol- } \\
\text { lar por las TIC en } \\
\text { clases de Ciencias }\end{array}$ & $\begin{array}{l}\text { Aprendizaje del } \\
\text { saber de las } \\
\text { ciencias que las } \\
\text { TIC podrían } \\
\text { favorecer }\end{array}$ & $\begin{array}{l}\text { Recursos digitales } \\
\text { posibles de utilizar }\end{array}$ \\
\hline $\begin{array}{l}\text { Facilitar el acceso } \\
\text { a la información en } \\
\text { distintos formatos } \\
\text { comunicacionales y } \\
\text { niveles } \\
\text { representacionales. } \\
\text { Simular fenómenos } \\
\text { naturales. }\end{array}$ & $\begin{array}{l}\text { Construcción de } \\
\text { conocimiento } \\
\text { teórico (conceptos, } \\
\text { leyes, modelos, } \\
\text { teorías). Desarrollo } \\
\text { de pensamiento } \\
\text { crítico y reflexivo } \\
\text { para seleccionar, } \\
\text { analizar, } \\
\text { interpretar la } \\
\text { diversidad de } \\
\text { información y } \\
\text { fuentes aportadas. }\end{array}$ & $\begin{array}{l}\text { Navegadores de } \\
\text { Internet. } \\
\text { Enciclopedia } \\
\text { Multimedia. } \\
\text { Videos - tutoriales } \\
\text { Simulaciones. } \\
\text { Animaciones. }\end{array}$ \\
\hline $\begin{array}{l}\text { Simular } \\
\text { experimentos. } \\
\text { Facilitar el } \\
\text { registro, } \\
\text { organización y } \\
\text { procesamiento de } \\
\text { datos, a partir de } \\
\text { la construcción de } \\
\text { tablas y/o gráficos. } \\
\text { Facilitar la } \\
\text { construcción de } \\
\text { modelos y la } \\
\text { interpretación de } \\
\text { la relación entre el } \\
\text { comportamiento } \\
\text { que se visualiza y } \\
\text { las expresiones } \\
\text { matemáticas que } \\
\text { modelan ese } \\
\text { comportamiento. } \\
\text { Facilitar la } \\
\text { comunicación a } \\
\text { partir de distintos } \\
\text { formatos. }\end{array}$ & $\begin{array}{l}\text { Desarrollo de } \\
\text { habilidades } \\
\text { relacionadas con la } \\
\text { experimentación } \\
\text { como: diseñar } \\
\text { montajes; realizar } \\
\text { mediciones; tomar, } \\
\text { registrar, organizar } \\
\text { e interpretar datos; } \\
\text { comunicar } \\
\text { resultados y } \\
\text { conclusiones. } \\
\text { Desarrollo de } \\
\text { habilidades } \\
\text { relacionadas con la } \\
\text { resolución de } \\
\text { problemas como: } \\
\text { registrar datos en } \\
\text { distintas fuentes; } \\
\text { organizarlos y } \\
\text { procesarlos; } \\
\text { comunicar } \\
\text { resultados. }\end{array}$ & $\begin{array}{l}\text { Procesadores de } \\
\text { texto. Hojas de } \\
\text { cálculo. } \\
\text { Simulaciones } \\
\text { Laboratorios } \\
\text { virtuales. } \\
\text { Graficadores. } \\
\text { Editores de } \\
\text { animaciones y } \\
\text { videos. } \\
\text { Herramientas de } \\
\text { modelado } \\
\text { dinámico. Editor } \\
\text { de esquemas } \\
\text { conceptuales. }\end{array}$ \\
\hline $\begin{array}{l}\text { Posibilitar el } \\
\text { conocimiento de } \\
\text { múltiples y } \\
\text { variadas } \\
\text { situaciones, } \\
\text { problemas, } \\
\text { contextos que } \\
\text { denotan la } \\
\text { aplicación de las } \\
\text { ciencias y la } \\
\text { tecnología. } \\
\text { Facilitar la } \\
\text { comunicación y el } \\
\text { trabajo } \\
\text { cooperativo. }\end{array}$ & $\begin{array}{l}\text { Desarrollo de } \\
\text { actitudes positivas } \\
\text { hacia la ciencia, su } \\
\text { producción y } \\
\text { aprendizaje. } \\
\text { Desarrollo de } \\
\text { actitudes de } \\
\text { respeto a la } \\
\text { diversidad de ideas } \\
\text { y de una conciencia } \\
\text { intercultural. }\end{array}$ & $\begin{array}{l}\text { Navegadores de } \\
\text { Internet. } \\
\text { Plataformas } \\
\text { virtuales - redes } \\
\text { sociales. }\end{array}$ \\
\hline
\end{tabular}

- superar la "transparencia representacional" que caracteriza al saber intuitivo para asumir que las representaciones no son la realidad misma y que además existen maneras alternativas de interpretar y explicar los fenómenos que suceden,
- superar la tendencia a sustancializar los fenómenos y a explicarlos en términos de estados o causalidades líneas simples (desconociendo la multiplicidad de variables en juego) para reconocer todos los elementos involucrados y los procesos de interacción que se dan entre ellos.

- adquirir razonamientos sistémicos lo que implicará la paulatina superación de razonamientos monovariados, lineales, unidireccionales, reduccionistas.

- Conocer la metodología que la comunicad científica implementa para construir nuevos conocimientos y reconocer la naturaleza representacional de los mismos

- Desarrollar la habilidad cognitiva de gestionar entre múltiples ideas que al aprender ciencia dispondrá en su mente, para elegir con criterio y fundamentos cuál elegir para resolver un problema o tomar y argumentar una decisión ante situaciones que involucren saber científico - tecnológico. Esto a su vez implicará (entre otros aspectos):

- aprender a resolver problemas, y con ello desarrollar habilidades procedimentales, cognitivas y meta cognitiva asociadas a esta tarea

- aprender a usar las nuevas tecnologías para aprender; para buscar información, transformarla en conocimiento y luego en "acción" al usarlo para resolver esos problemas que la sociedad actual le plantea.

\section{IDAS: Una Propuesta de Enseñanza $(\mathrm{PE})$}

Atendiendo a las ideas anteriormente descriptas que conforman el marco teórico adoptado y a fin de favorecer el aprendizaje desde esa perspectiva, se ha diseñado la PEIDAS. Esta propuesta pretende favorecer la comprensión de conceptos, leyes y teorías de la física en el contexto de la educación media como así también el desarrollo de competencias y habilidades relacionadas a la resolución de problemas y al uso crítico y estratégico de las TIC.

La PE-IDAS contempla cuatro instancias didácticas: INICIACIÓN, DESARROLLO, APLICACIÓN y SÍNTESIS. A continuación, se describen los objetivos y metodologías de cada fase y se utiliza a modo de dejemplo, la secuencia de enseñanza diseñada para el abordaje de la Óptica Geométrica [29, 30] cuya potencialidad para favorecer los aprendizajes deseados ha sido validada en investigaciones previas [31.

\subsection{Instancia de Iniciación}

Asumiendo que la adquisición de significado lógico y psicológico por parte de quien aprende, provee de mejores 
perspectivas para la construcción de nuevos saberes y nuevas formas de conocer, la etapa de Iniciación reviste gran importancia. Aquí se busca favorecer la toma de conciencia y el reconocimiento del modo de conocer que tiene el alumno que se enfrenta a una tarea. A su vez, permite al docente contar con pautas e indicadores concretos para pensar y formular acciones que favorezcan el desarrollo de los modos de pensar con que sus estudiantes llegan al aula.

En esta primera instancia de la PE se busca que los estudiantes:

- se motiven por aprender acerca de la temática que se abordará, mediante el planteo de situaciones y problemas sencillos;

- expliciten sus ideas respecto de dicha temática;

- reconozcan las imprecisiones, inconsistencias y/o el limitado poder explicativo que suelen tener esas ideas;

- se interesen en conocer las ideas científicas, es decir conceptos, modelos, leyes... que la ciencia propone respecto de la temática que comienza a estudiarse.

Para lograr estos objetivos se presentan diversas actividades que requieren el análisis, explicación, interpretación o predicción de algún fenómeno y/o la fundamentación o descripción del funcionamiento de algún dispositivo tecnológico. Las mismas se secuencian de forma tal que demandan respuestas cuya complejidad va en aumento en cuanto al conocimiento requerido para su elaboración

Con estas tareas no sólo se busca que los alumnos reconozcan y expliciten sus concepciones sino también que comiencen a identificar y reconocer sus características implícitas, tales como el bajo poder explicativo o su carácter reduccionista. Así, las primeras actividades propuestas involucran el análisis de fenómenos observables en su cotidianeidad y/o dispositivos sencillos conocidos por los estudiantes, y sobre los cuales podrán elaborar una posible explicación basándose en las ideas que poseen.

Para el caso de la PE de Óptica Geométrica una de las actividades de iniciación plantea ${ }^{1}$

\footnotetext{
1 Trabajos de investigaciones previos (véase por ejemplo 31]) revelan que los estudiantes, por lo general, logran elaborar una respuesta a estas preguntas basándose en el saber construido a partir de experiencias y observaciones cotidianas (como "mirar" objetos a través de botellas/jarras con agua) o más formales (es una práctica habitual que desde los primeros años de escolaridad se usen lupas para observar objetos pequeños). Pero dichos resultados también revelan que las explicaciones elaboradas tienden a ser reduccionistas, en tanto tienden a explicar que las imágenes se forman "gracias" a las lentes (y por las propiedades que ésta tiene) desconociéndose el rol de la luz y/o el observador, y de los procesos luz - lentes - sistema visual, durante el proceso de formación y visión de imágenes ópticas. Por eso se les sugiere, además de usar las ideas que tienen, interactuar con simulaciones que representan los mencionados fenómenos. Esto con el fin de estimular que pongan atención a ellos e intenten una interpretación/explicación inicial.
}

1. Observa la fotografía 1 e intenta explicar por qué vemos un ojo grande y otro pequeño.

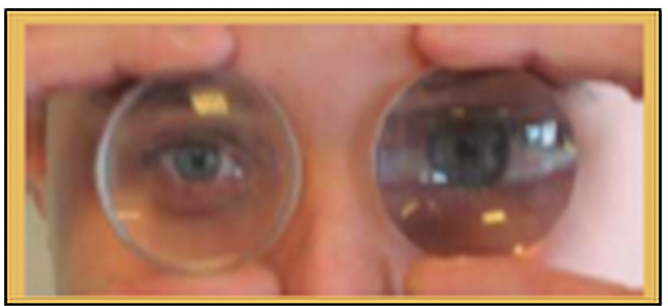

2. Si en tu respuesta anterior le "echaste la culpa" a los vidrios que el joven se colocó ante sus ojos, responde:

(a) ¿Cuál es la diferencia entre esos vidrios para hacer que veamos sus ojos tan diferentes?

(b) ¿Qué fenómenos ocurren en cada vidrio cuando la luz incide en ellos?

Para responder las siguientes preguntas usa, además de tus propias ideas, la información aportada por las simulaciones Geometric-optics (disponible en https:// phet.colorado.edu/es/simulation/legacy/geometricop tics) y/o Ray Optics (disponible en Play Store.)

Como puede observarse a través de este ejemplo, con el fin de ayudar a los estudiantes a reconocer la necesidad e importancia de conocer el saber de la ciencia y motivar su estudio, se les presentan problemáticas que involucran fenómenos potencialmente significativos e interesantes para ellos, pero cuya resolución implica un conocimiento más complejo que el que podrían haber construido hasta el momento, ya sea intuitivamente o a partir de su educación formal previa.

Dentro de esta misma fase y en otra actividad, se plantea analizar dos dispositivos tecnológicos como el "tubo solar" y el proyector de diapositivas:

1. Con el objetivo de aprovechar la energía solar para iluminar los hogares, se han comenzado a utilizar los llamados "tubos solares". Éstos consisten en una serie de espejos colocados estratégicamente dentro de un tubo para logar que la luz del Sol llegue al interior de la casa. ¿Cómo explicarías el funcionamiento de dicho tubo?

2. Si te solicitan diseñar un proyector capaz de generar una imagen que tenga el doble del tamaño de la diapositiva:

(a) ¿Qué datos necesitarías conocer para poder cumplir con esta tarea?

(b) Con esos datos, ¿cuál sería tu incógnita?

(c) ¿Cómo la calcularías?

Como actividad final de esta etapa se les propone a los estudiantes la elaboración de un esquema conceptual. Esta tarea tiene como objetivo, además de seguir favoreciendo la explicitación y clarificación de ideas, que 
cada alumno cuente con un esquema, una especie de "polaroid2" que represente su conocimiento inicial y cuya evaluación se propondrá en la instancia final. Así y para el caso de la PE de óptica se les propone como última tarea:

Elabora un esquema conceptual donde queden de ma-
nifiesto los elementos necesarios y los procesos involu-
crados en el fenómeno de formación de imágenes. Para
realizar el esquema usa el programa CmapTools o la
aplicación Simmple Mind Free Maps. Guarda el mapa
confeccionado porque volveremos a él para evaluarlo,
corregirlo, ampliarlo.

Como ya se ha mencionado y siendo el objetivo de la INICIACIÓN que cada estudiante exprese y reconozca sus ideas, se propone que las actividades que conforman esta instancia sean resueltas en primera instancia de forma individual, para luego socializar con los pares las respuestas elaboradas.

Es en esa socialización donde el docente tiene un rol más activo y central ya que debe alentar y estimular a los estudiantes a compartir sus ideas, a confrontarlas con las de los demás, a argumentar a favor o en contra de alguna de ellas en caso de existir discrepancias y ayudarlos a clarificar el conocimiento que poseen, a identificar lo que falta por conocer y a reconocer la necesidad (e importancia) de aprender las ideas propuestas desde el saber científico. Todo, sin perder de vista que no se pretende en esta fase respuestas completas y próximas a las de la ciencia escolar sin explicitación y socialización de las ideas que los estudiantes poseen.

En el Cuadro 3 se sintetizan algunas estrategias docentes que resultarían eficaces implementar para alcanzar los objetivos centrales de esta etapa, según lo hallado en investigaciones realizadas [32, 33].

\subsection{Instancia de desarrollo}

Mientras que desde la ciencia los fenómenos se interpretan como sistemas de relaciones de interacción entre las múltiples variables que lo conforman, son numerosos los trabajos de investigación que han hallado que los alumnos, al llegar al aula, tienden a usar un saber intuitivo para explicar los tópicos que se abordan con la enseñanza científica en educación media. Y es desde este saber que tienden a interpretar y explicar los fenómenos en términos mono variados y reduccionistas, reconociendo sólo algunos de los elementos involucrados y desconociendo los procesos de interacción entre ellos.

Con la instancia de desarrollo en la PE-IDAS no "sólo" se busca favorecer la comprensión de los conceptos, leyes y modelos asociados con la temática a abordar, sino que se pretende la complejización del modo de

\footnotetext{
2 Término empleado para hacer alusión a una impresión instantánea, una foto de la organización y de las relaciones entre los conceptos que cada estudiante es capaz de establecer y/o generar al comienzo de la PE.
}

Cuadro 3: Estrategias docentes sugeridas para la instancia de iniciación.

\begin{tabular}{|c|c|}
\hline Objetivo & Posible Accionar Docente \\
\hline $\begin{array}{l}\text { Indagar ideas } \\
\text { previas o } \\
\text { alternativas de } \\
\text { los alumnos }\end{array}$ & $\begin{array}{l}\text { Profundizar con los estudiantes las } \\
\text { respuestas dadas a las actividades } \\
\text { individuales sobre el fenómeno en estudio. } \\
\text { Incentivar la expresión oral de las } \\
\text { respuestas dadas. } \\
\text { Solicitar explicaciones-justificaciones de las } \\
\text { propias ideas. }\end{array}$ \\
\hline $\begin{array}{l}\text { Clarificar y } \\
\text { describir ideas } \\
\text { de los alumnos } \\
\text { Propiciar la } \\
\text { discusión y la } \\
\text { construcción } \\
\text { colectiva de } \\
\text { conocimiento }\end{array}$ & $\begin{array}{l}\text { Comunicar ante el gran grupo ideas - } \\
\text { justificaciones de los alumnos. } \\
\text { Favorecer la evaluación de pares de las } \\
\text { ideas propuestas por los alumnos. } \\
\text { Orientar a los estudiantes a la } \\
\text { verbalización de sus ideas ante los pares, } \\
\text { con justificación y argumentaciones. } \\
\text { Comparar ideas propuestas por alumnos } \\
\text { para destacar características comunes y } \\
\text { relevantes. }\end{array}$ \\
\hline $\begin{array}{l}\text { Sintetizar ideas } \\
\text { de los alumnos }\end{array}$ & $\begin{array}{l}\text { Registrar las ideas manifestadas a fin de } \\
\text { que sean reconocidas y visualizadas por } \\
\text { todos. } \\
\text { Destacar las limitaciones de } \\
\text { explicaciones-justificaciones. }\end{array}$ \\
\hline
\end{tabular}

conocer empleado por quienes aprenden (y con ello de los principios ontológicos y conceptuales subyacentes y modos de razonar asociados). Por ello, durante la instancia de desarrollo se sigue un camino particular que conduce a la:

1. identificación/visualización del fenómeno a estudiar a fin de conocerlo o reconocerlo y describirlo;

2. identificación de las variables de las que depende y/o elementos involucrados;

3. identificación y establecimiento de la interrelación entre dichas variables y/o de los elementos involucrados;

4. indagación sobre el significado de los conceptos y enunciado de la ley subyacente;

5. enunciación del concepto/ley usando el lenguaje coloquial y simbólico y aplicación para la resolución de un problema sencillo.

Si bien las actividades involucradas en esta instancia son variadas, sin duda los trabajos experimentales, ya sea en laboratorios reales o virtuales, ocupan un lugar central.

Para el desarrollo de trabajos virtuales se utilizan simulaciones, ambientes virtuales altamente interactivos (en inglés, Highly Interactive Virtual Environments, HIVE) que permiten a los sujetos visualizar fenómenos y procesos físicos; interactuar, manipulando y transformando objetos en la interfaz de la aplicación y hasta realizar experiencias simuladas de difícil ejecución en el laboratorio.

La potencialidad de estos recursos se basa en la positividad de representar de forma dinámica el funcionamiento de un sistema, permitiendo la visualización de procesos involucrados y mostrando la interacción entre 
sus componentes y/o consecuencias de tales interacciones dinámicas en la evolución de dicho sistema [26]. Así, las simulaciones permiten al sujeto extender y amplificar procesos cognitivos, ayudándolos a resolver problemas complejos y ambiguos, y dar sentido al conocimiento científico; a la vez que se los involucra en el manejo de una amplia gama de códigos científicos y tecnológicos.

En palabras de Lévy 24, la simulación es un modo de conocimiento propio de la cibercultura que trata de una tecnología intelectual que multiplica la imaginación individual (aumento de la inteligencia) y permite a los sujetos compartir, negociar y refinar modelos mentales comunes (aumento de la inteligencia colectiva).

El uso de simulaciones no reemplaza los razonamientos humanos, sino que prolongan y transforman las capacidades de imaginación y de pensamiento, actuando como próstesis cognitivas facilitadora de nuevos aprendizajes [5]. De forma análoga el trabajo experimental en laboratorio virtual no intenta reemplazar al trabajo en el laboratorio real, sino que se consideran recursos e instancias didácticas complementarias potencialmente útiles para favorecer un aprendizaje integral de las ciencias y la tecnología.

A continuación, se ejemplifica esta secuencia que guía el trabajo en la fase de Desarrollo para el abordaje de conceptos y leyes asociados a la Óptica geométrica.

1. Para favorecer la identificación del fenómeno a estudiar se propone la siguiente tarea:

(a) Mira con atención la fotografía 2 que muestran la trayectoria que sigue la luz antes y después de incidir en una lente a. Convergente b. Divergente (puedes imitar el experimento haciendo uso de un láser y una lente o interaccionando con la simulación disponible en las simulaciones Geometric-optics (disponible en https://phet.colorado.edu/es/simulatio $\mathrm{n} /$ legacy/geometricoptics) y/o Ray Optics (disponible en Play Store.)

(b) Describe la trayectoria seguida por la luz en cada caso.
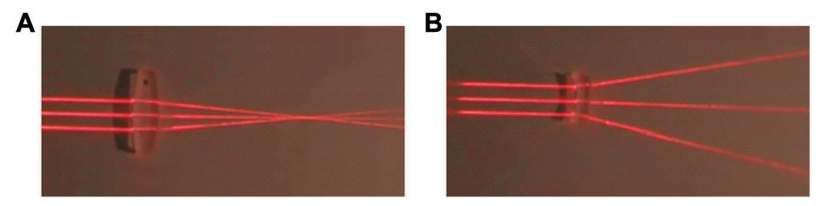

(c) Identifica el fenómeno que ocurre cuando la luz se transmite por estas lentes y, atendiendo a ello, interpreta las diferencias observadas.

2. Para favorecer la identificación de las variables involucradas en el fenómeno:

Descarga en tu computadora el laboratorio virtual Geometric-optics. (a) Interactuando con la simulación, mueve el objeto a lo largo del eje de la lente y observa con qué tipo de lente se puede generar una imagen real.

(b) Elige trabajar con ese tipo de lente y describe las imágenes que se forman conforme modificas la distancia objeto - lente (¿tienen siempre el mismo tamaño? ¿son derechas o invertidas?, ¿son reales o virtuales? ¿Por qué? ¿Necesitan siempre de una pantalla para ser observadas? ¿Por qué?)

3. Para ayudar a los alumnos a reconocer la identificación de la relación entre dichas variables e indagar sobre la ley involucrada se les propone tareas como:

(a) Para realizar el siguiente experimento virtual, descarga la aplicación SimRi Simulación de Rayos e Imágenes. a. Con la información aportada por la simulación, realiza una tabla en donde detalles el valor de $s, x$, aumento $y$ orientación de la imagen para los intervalos: $s<2 f, 2 f<s<f$ y $s<f$.

(b) Analiza cómo varía $x$ y el aumento al variar $s$ en cada intervalo y concluye para cada uno de ellos cómo resulta ser la imagen que se forma: real o virtual, derecha o invertada, aumentada o disminuida.

4. Para estimular a los alumnos a enunciar la ley involucrada se les pide que:

A partir de las conclusiones que surjan: a. Expresa cómo se relacionan CUANTITATIVAMENTE $s, x$ y $f$ (dist. Focal). b. Comprueba que esta relación se cumple para distintos valores de $s, x$ y $f$ (dist. Focal), utilizando la simulación anterior. c. Analiza el rol de cada uno de los elementos de estos sistemas ópticos: objeto/fuente, lente y pantalla.

Como se adelantó, las actividades experimentales virtuales o reales cumplen un lugar central en la instancia de desarrollo de las PE IDAS pero no son el único tipo de tareas involucradas. A éstas se les suman otras como realizar búsqueda, análisis, interpretación y uso crítico de información; explicar algún fenómeno natural y/o el funcionamiento de un dispositivo tecnológico; exponer y defender ideas al elaborar una argumentación, diseñar y ejecutar trabajos experimentales. Pero más allá del tipo de tarea, el carácter distintivo de todas las actividades propuestas es que sean los alumnos quienes, trabajando en equipo y cooperativamente, participan activamente en la construcción de los conceptos y leyes. Se intenta con ello, que la metodología de trabajo en esta fase de desarrollo sea coherente con aquella que la comunidad científica lleva adelante en la construcción social del conocimiento.

El docente en esta instancia es apartado inicialmente del escenario central evitando la tendencia a las clases magistrales. Sin embargo, no puede desconocerse el rol 
que cumple como guía, orientador y moderador del aprendizaje en la PE-IDAS. Algunas estrategias docentes que, según investigaciones previas 32 34] resultarían eficaces para alcanzar los objetivos centrales de esta etapa, implicarían:

- supervisar el trabajo de los distintos grupos, acompañando en las observaciones, orientando con preguntas y promoviendo procesos de pensamiento, reflexión, retroalimentación,

- estimular la participación de los alumnos al resolver las actividades planteadas ayudándolos a analizar los datos, identificar regularidades en el comportamiento de las variables involucradas,

- utilizar las conclusiones arribadas por cada grupo para guiarlos en el reconocimiento de las variables involucradas en la producción del fenómeno estudiado y de los procesos que deben darse para que este se produzca.

- realizar preguntas para promover la participación y monitorear si los estudiantes van entendiendo el tema,

- llevar adelante una exposición dialogada que permita a los alumnos compartir y discutir ideas propias con las que el docente comunica y así arribar juntos, a los principales conceptos bajo estudio,

- promover una reflexión consciente sobre la comprensión (o no) del tema y con ello del aprendizaje experimentado,

- motivarlos para que se involucren en cada tarea propuesta, cuidando de dar valor a lo que cada alumno exprese y comparta,

- sintetizar/presentar/exponer los conceptos y leyes de la ciencia a partir de las ideas que los estudiantes vayan explicitando conforme resuelven las actividades planteadas.

\subsection{Instancia de aplicación}

Como se fundamentó en la introducción de este trabajo, el aprendizaje de las ciencias no implica "sólo" la comprensión de los conceptos, leyes, teorías propuestas por la comunidad científica, sino también el desarrollo de la capacidad de aplicar el nuevo conocimiento para explicar múltiples y "novedosas" situaciones. Es por ello que la instancia de aplicación es de primordial importancia, en tanto se busca potenciar el desarrollo de la habilidad de gestionar y hacer uso consistente y coherente del saber construido como así también desarrollar destrezas inherentes a la resolución de problemas.

Para lograr este propósito se diseñan actividades que implican la transferencia de las "nuevas" concepciones en múltiples contextos y situaciones, que incluyen en sus planteos situaciones problemáticas que involucran escenarios y/o fenómenos conocidos y potencialmente significativos para los estudiantes.
Para delinear las situaciones problemáticas se adoptó la clasificación que [35] realizan en relación a los posibles tipos de problemas con los que nos podemos encontrar: indefinidos, definidos y bien definidos. Dichos autores clasifican como "indefinidos" a aquellos problemas que carecen de información necesaria para llegar a la solución y requieren que quienes los resuelvan se planteen objetivos para obtener respuestas al problema planteado, por lo que las soluciones a las que se arriban se pueden construir por diferentes caminos.

Entre los incluidos en la categoría "definidos" se encuentran aquellos para los cuales la especificación del problema es incompleta por lo que dan lugar a múltiples soluciones posibles que no son equivalentes, pero igualmente válidas, es decir no hay solución definitiva en la que los expertos puedan acordar, por ejemplo. En el otro extremo de esta clasificación se encuentran los "bien definidos" que son aquellos cuyo enunciado presenta toda la información necesaria para ser resueltos, por lo que no es necesario explicitar objetivos y la resolución se lleva a cabo por un único camino. La diferencia básica entre los "problemas bien definidos" y los "problemas indefinidos" radica, por lo tanto, en la cantidad de condicionamientos o grados de libertad a los que se encuentran restringidos cada uno.

Con la PE-IDAS se busca formar estudiantes capaces de resolver problemas como los que se encontrarán en su vida cotidiana, que asumimos y clasificamos como problemas abiertos planteados en forma indefinida, para cuya resolución se debería desplegar estrategias como las propuestas en el Cuadro 1. Oliveira, Solano Araujo y Veit [36] advierten que existe consenso respecto a que este tipo de problemas puede contribuir significativamente al aprendizaje no sólo de conceptos de Física sino también de conocimiento procedimental y actitudinal dado que favorecen el trabajo colaborativo y facilitan la transición entre las experiencias de la vida cotidiana y la comprensión de conceptos físicos; estimulan la participación activa de los estudiantes y favorecer la superación de las dificultades conceptuales y epistemológicas que suelen manifestarse asociadas al aprendizaje.

Pero trabajos de investigación previos (véase por ejemplo [19, 37]) dejan en evidencia la complejidad que implica para los alumnos resolver este tipo de tareas en el contexto de las clases de Física. Por ello y para favorecer el desarrollo paulatino de las habilidades involucradas, en las PE diseñadas se incorporan problemáticas con un grado creciente y progresivo de complejidad e indefinición.

Así, en primera instancia se plantean enunciados definidos cuya resolución implica utilizar de forma directa el concepto/ley y hallar un resultado. Gradualmente se plantean problemas más abiertos donde es necesario buscar datos (en la bibliografía o a través de una actividad experimental real o virtual) y/o buscar/decidir la vía de resolución. Hacia el final se propone la resolución de 
un problema llamado desafío ante el cual los estudiantes deben proponer el diseño (o construir) un dispositivo tecnológico o explicar un determinado fenómeno. Este desafío implica la integración de los contenidos analizados como así también la búsqueda bibliográfica de datos, información relevante y hasta de nuevos conocimientos (relacionados con la Física como así también con otras disciplinas afines y la tecnología). Estos desafíos también demandan de la decisión del procedimiento a seguir y el análisis crítico del resultado/producto hallado en post de responder a la situación planteada. Dicha situación involucra temáticas de relevancia social que permiten apreciar la vinculación e impacto de la ciencia sobre la calidad de vida de las personas y el desarrollo de la tecnología. Se busca de esta manera generar espacios de reflexión y debate que favorezcan el desarrollo de una visión integral y humanística de las ciencias donde se reconozca su impacto para el desarrollo sustentable cultural y tecnológico de las sociedades.

A continuación, y a través de la PE de Óptica que se utiliza para ejemplificar, se enuncian los tipos de problemas que se han descripto anteriormente.

1. Problemas cerrados

Un objeto se ubica a $2 \mathrm{~cm}$ de una lente delgada convergente de distancia focal $f=150 \mathrm{~mm}$. Calcula la posición donde se generará la imagen y descríbela (indicando si es real o virtual; derecha o invertida; aumentada o disminuida).

2. Problemas de indefinición creciente

(1) La fábrica Lentille y Mince diseña y construye, entre otros dispositivos ópticos, proyectores de diapositivas. Como saben de tus conocimientos, te ofrecen trabajar en el Departamento de Diseño. Como primeras tareas deberás:

(a) Diseñar un proyector de diapositivas capaz de formar una imagen de 1 metro de altura de una diapositiva de $5 \mathrm{~cm}$ de altura. Dicho diseño implica que especifiques todos los parámetros que fijarás, así como también el valor o rango de valores que pueden tomar la/s variable/s que deba manipular el usuario.

(b) Evaluar si alguna/s de las lentes que ellos tallan (cuyas distancias focales son de 5, 15 22 y $148 \mathrm{~cm}$ ) podrán ser usadas para fabricar los proyectores deseados o deberán tallarse otras.

(c.) De no servir las lentes que ya tienen talladas, indica la distancia focal que deberían tener.

(2) Supone ahora que cuentas con una lupa de $150 \mathrm{~cm}$ de distancia focal y deseas usarla para proyectar una imagen del sol sobre el patio de tu casa. (a) ¿A qué distancia del suelo ubicarías la lupa para que se forma una imagen nitida?

(b) ¿Cuentas con todos los datos para resolver el problema o te faltaba alguno?

(c) Si te falta algún dato: ¿podrías estimarlo para hallar una respuesta aproximada a la real? Si no puedes estimarlo, ¿dónde lo buscarías?

(3) Investiga sobre la conformación del ojo humano y explica, sobre la base de todo lo analizado hasta aquí:

(a) La formación de la imagen retiniana y el proceso de acomodación en un ojo normal.

(b) La visión no nítida de un ojo miope. Pueden resultarte útiles las simulaciones disponibles en disponible en http://ww w.vascak.cz/data/android/physicsatsc hool/template.php?s=opt_akomodace\&l $=\mathrm{en \& zoom}=\|$ http: $/ /$ www.vascak.cz $/$ da ta/android/physicsatschool/template. php?s=opt_vady\&l=es\&zoom $=0$

3. Problemas desafíos

Este desafío final consiste en convertir a un dispositivo móvil (el celu o la tablet) en un cine. Para ello deberás:

(1) Diseñar y construir un proyector que permita generar una imagen ampliada de la pantalla del dispositivo móvil (y así poder ver "tamaño cine" las películas que normalmente ves "tamaño visor").

(2) Decidir justificadamente qué tipo de lente usar (especificando sus características) y determinar, haciendo los cálculos pertinentes, a qué distancia deberían ubicarse la lente, el dispositivo móvil y la pantalla para lograr una imagen nítida. Calcula el tamaño lateral que tendrá la imagen proyectada.

Este nuevo desafío consiste en diseñar y construir una "lámpara de agua". Para ello deberás realizar las siguientes tareas.

(1) Busca información sobre el proyecto "Un litro de luz"

(2) Construir la lámpara de agua y comprobar su funcionamiento

(3) Elaborar un informe donde se presente y describa el dispositivo construido, se expliciten los cálculos realizados para que éste funcione correctamente y se explique "científicamente" dicho funcionamiento.

Todas estas actividades están pensadas para ser resueltas en grupos, favoreciendo el trabajo en equipo y el aprendizaje "de y a través" de otros. El docente, nuevamente, cumple el rol de guía y moderador. 
En el Cuadro 4 se sintetizan algunas estrategias docentes que, según investigaciones previas citadas con antelación, resultarían eficaces para alcanzar los objetivos centrales de esta etapa.

Cuadro 4: Estrategias docentes sugeridas para la instancia de aplicación.

\begin{tabular}{|c|c|}
\hline Objetivo & Accionar Docente Sugerido \\
\hline $\begin{array}{l}\text { Promover } \\
\text { participación de } \\
\text { los alumnos, } \\
\text { explicitando sus } \\
\text { ideas y } \\
\text { explicaciones }\end{array}$ & $\begin{array}{l}\text { Recuperar y socializar } \\
\text { respuestas-explicaciones de alumnos a } \\
\text { actividad previa. } \\
\text { Preguntar para que reconozcan variables } \\
\text { que intervienen en situación - problema, } \\
\text { sus funciones y sus interacciones. } \\
\text { Guiar en el uso de modelos de la ciencia } \\
\text { para explicar. } \\
\text { Propiciar la elaboración de } \\
\text { argumentaciones. } \\
\text { Orientar en la elaboración de argumentos } \\
\text { para explicar. }\end{array}$ \\
\hline $\begin{array}{l}\text { Clarificar las } \\
\text { ideas de los } \\
\text { alumnos }\end{array}$ & $\begin{array}{l}\text { Explicar situaciones planteadas en las } \\
\text { actividades previas. } \\
\text { Destacar e informar sobre las variables que } \\
\text { intervienen en situación - problema, sus } \\
\text { funciones y sus interacciones. }\end{array}$ \\
\hline $\begin{array}{l}\text { Sinterizar el } \\
\text { modelo de } \\
\text { ciencia usado y } \\
\text { el tipo de } \\
\text { explicaciones } \\
\text { elaboradas }\end{array}$ & $\begin{array}{l}\text { Realizar una síntesis del modelo usado. } \\
\text { Explicitar las características de una } \\
\text { explicación usando nuevas ideas (de la } \\
\text { ciencia). } \\
\text { Establecer diferencias entre explicaciones } \\
\text { cotidianas y las coherentes con las de la } \\
\text { ciencia. } \\
\text { Evaluar la aplicación de las ideas de la } \\
\text { ciencia. } \\
\text { Sintetizar el saber de la ciencia implicado. }\end{array}$ \\
\hline
\end{tabular}

\subsection{Instancia de síntesis}

La instancia de síntesis es un momento crucial para que docente y alumnos evalúen los aprendizajes propiciados por la enseñanza. Esto no implica que la evaluación se considere reducida a una única instancia final. Por el contrario, desde la PE-IDAS se concibe que cada una de las actividades realizadas en las etapas anteriores otorgan datos a alumnos y docentes para poder regular los procesos de enseñanza y de aprendizaje. Pero sí se considera este momento final como uno especialmente propicio para que los estudiantes sean conscientes de qué han aprendido (y qué falta por aprender) como así también de cómo aprendieron, esto es, de cuáles fueron los cambios en sus puntos de vista, en su manera de pensar, de planificar la resolución de un problema, de abordar situaciones no conocidas, de fundamentar teóricamente resultados, entre otras muchas más. Se busca así favorecer que los estudiantes desarrollen actitudes críticas sobre el propio proceso de aprendizaje (reconociéndose como los principales artífices del mismo) e identifiquen y reconozcan aquellas herramientas que les resultaron útiles y podrán seguir usando para seguir aprendiendo.
Para favorecer el alcance de estos objetivos, las tareas involucradas en esta instancia de síntesis, invitan a los alumnos a comparar sus ideas iniciales con las compartidas luego de la enseñanza y analizar las características de uno y otro modo de conocer. A su vez se propone la resolución de problemáticas que contemplan situaciones "novedosas" (cuyo planteo involucre situaciones/contextos diferentes para cuya resolución los alumnos puedan desplegar todas las herramientas adquiridas/desarrolladas durante la PE) con el fin de que, junto al docente, puedan también evaluar la capacidad desarrollada respecto del uso de las nuevas ideas para resolver diversos problemas.

Como actividad de síntesis de la PE de Óptica se propuso la siguiente actividad.

(1) Relee las respuestas que elaboraste en la sección ¡A pensar y a elaborar predicciones! $Y$, sobre la base de lo estudiado hasta aquí, modifícalas y/o amplíalas.

(2) Has lo mismo con el esquema conceptual que elaboraste en esa oportunidad. No dejes de incluir ahora los conceptos imagen optica; imagen real; imagen virtual, lentes convergentes, lentes divergentes, ecuación de las lentes delgadas, además de todos aquellos que consideres pertinentes.

El rol del docente nuevamente resulta crucial, no sólo como "evaluador" (y eventualmente, "ponderador" dadas las condiciones que cada sistema educativo establece) de los aprendizajes de los estudiantes sino, fundamentalmente, como guía para la autoevaluación que se espera ellos realicen. En el Cuadro 5 se sintetizan algunas estrategias docentes que, según investigaciones previas citadas con antelación resultarían eficaces para alcanzar los objetivos centrales de esta etapa.

\section{Metodología Empleada para El Diseño y Validación de las PE IDAS}

Para diseñar y evaluar las PE-IDAS se implementó la metodología de Investigación Basada en Diseño (IBD), que ha comenzado a consolidarse como un paradigma metodológico de gran potencial para hacer progresar las teorías de aprendizaje y de enseñanza en situaciones reales [38] a partir del diseño y desarrollo de innovaciones educativas que se implementan en los complejos escenarios que definen las aulas [2]. Esta propuesta metodológica involucra tres grandes etapas: 1) preparación del diseño, 2) implementación y 3) análisis retrospectivo [39].

En concordancia con lo dicho, el trabajo aquí presentado involucró las siguientes etapas:

- Diseño de las PE, lo que implicó definir metas de aprendizaje, describir condiciones iniciales o puntos de partida respecto de conocimiento de los alumnos, definir intenciones teóricas y desarrollar 
Cuadro 5: Estrategias docentes sugeridas para la instancia de síntesis.

\begin{tabular}{|c|c|}
\hline Objetivo & Accionar Docente Sugerido \\
\hline $\begin{array}{l}\text { Guiar a los } \\
\text { alumnos en la } \\
\text { identificación, } \\
\text { clarificación y } \\
\text { evaluación de } \\
\text { sus ideas usadas }\end{array}$ & $\begin{array}{l}\text { Socializar las explicaciones de los alumnos } \\
\text { y los modelos usados. } \\
\text { Explicar lo que se representa en cada } \\
\text { modelo. } \\
\text { Analizar la validez de esos modelos para } \\
\text { elaborar explicaciones, comparar distintos } \\
\text { modelos usados (variables, interacciones). } \\
\text { Ayudar a los alumnos a clarificar sus ideas } \\
\text { usadas a lo largo del proceso de enseñanza. }\end{array}$ \\
\hline $\begin{array}{l}\text { Analizar, con } \\
\text { los alumnos, el } \\
\text { aprendizaje } \\
\text { experimentado }\end{array}$ & $\begin{array}{l}\text { Compartir el cambio producido en la } \\
\text { manera en que se fue explicando durante } \\
\text { el proceso de enseñanza. } \\
\text { Reflexionar sobre las características del } \\
\text { proceso de aprendizaje experimentado. } \\
\text { Solicitar que verbalicen qué creen que } \\
\text { aprendieron. } \\
\text { Solicitar que verbalicen qué les ayudó más } \\
\text { a aprender. } \\
\text { Realizar una síntesis sobre qué } \\
\text { aprendieron y cómo. }\end{array}$ \\
\hline $\begin{array}{l}\text { Plantear } \\
\text { situaciones } \\
\text { cotidianas para } \\
\text { sintetizar y } \\
\text { aplicar el } \\
\text { modelo de la } \\
\text { ciencia escolar y } \\
\text { "evaluar" su } \\
\text { potencialidad } \\
\text { para elaborar } \\
\text { explicaciones }\end{array}$ & $\begin{array}{l}\text { Representar gráficamente el modelo de } \\
\text { ciencia escolar que se intentó construir con } \\
\text { la instrucción. } \\
\text { Explicitar situaciones que dicho modelo } \\
\text { permite explicar. } \\
\text { Proponer el análisis de situaciones } \\
\text { cotidianas donde se puede aplicar el } \\
\text { modelo de la ciencia para explicarlas. } \\
\text { Solicitar explicaciones de situaciones } \\
\text { cotidianas. } \\
\text { Imitar experimentalmente las situaciones a } \\
\text { analizar a fin de ayudar a los alumnos a } \\
\text { elaborar sus explicaciones. } \\
\text { Realizar preguntas para analizar } \\
\text { interacciones entre las variables } \\
\text { involucradas en las situaciones analizadas. }\end{array}$ \\
\hline
\end{tabular}

el diseño instructivo que debería llevar al logro de las metas fijadas.

- Implementación de las PE en el aula acompañada de un trabajo de investigación exploratorio que permitió la identificación de dificultades (de interpretación y comprensión de la información, de aprendizaje, etc.) que les ocasionó a los estudiantes (y docente implementador) la secuencia, tipos y/o cantidad de actividades; recursos incluidos. . . Esta etapa conllevó un trabajo continuo y colaborativo entre investigadores y docentes implementadores a fin de compartir los fundamentos y características de la PE (antes de su implementación) y reflexionar (durante y después de la implementación) sobre la propia implementación a fin de detectar aquellos aspectos (de las actividades de aprendizaje propuestas y del accionar docente) que favorecieron el aprendizaje y aquellos otros que deberían modificarse para que la enseñanza resulte más eficaz.

- Rediseño de la PE, atendiendo a los resultados hallados en la exploración y con el fin de introducir modificaciones tendientes a favorecer la superación de los problemas detectados.
- Implementación de algunas de las PE rediseñadas (tomadas a modo de estudio de caso) acompañada de un trabajo cuasi experimental con diseño pre, intervención, postest y análisis cuali y cuantitativo de los datos obtenidos de diferentes fuentes (observaciones de clase; diario del docente, cuaderno de los alumnos, cuestionarios) para estudiar y caracterizar el aprendizaje experimentado por los estudiantes y la influencia sobre ello de la PE y accionar del docente que la implementó.

- Rediseño de la PE, evaluación del marco teórico de referencia, socialización de resultados. Difusión de resultados entre la comunidad científica para abrir la posibilidad de dar mayor validez a la propuesta.

Las fases de la metodología empleada se sintetizan en la Figura 4

\section{Algunos Resultados Alcanzados}

\subsection{Sobre el material didáctico diseñado}

En los últimos años y a partir de las primeras experiencias en el campo de la Optica, se ha avanzado con nuevas PE-IDAS que abordan temáticas relacionadas con la Mecánica Clásica y el Electromagnetismo. Las mismas están siendo transformadas en libros digitales destinados a alumnos/as de educación secundaria, compilados bajo el título "Física y Tic, la dupla del siglo". En el primero de la serie [29], titulado "La Energía", se abordan conceptos y fenómenos relacionados con la energía mecánica, la eléctrica y la lumínica. El segundo, titulado "Las Interacciones", se abordan las leyes de Newton y se tratan las interacciones gravitatoria, eléctrica, magnética y electromagnética ${ }^{3}$

También se han elaborado recursos tecnológicos para acompañar la enseñanza de la Física como el video juego "The fem" 40, 41].

Todos los materiales diseñados están disponibles en la página web de Ipact (https://programaipact.wixs ite.com/programaipact) y se puede acceder a ellos de forma libre y gratuita, intentando de este modo democratizar el saber y favorecer una alfabetización científico y tecnológicas para todos.

\subsection{Sobre la formación docente continua}

Diseñadas las PE-IDAS se realizaron cursos destinados a docentes y futuros docentes de educación secundaria (potenciales implementadores de las $\mathrm{PE}$ ) donde se compartieron los fundamentos científico - didácticos que subyace a ellas. Los mismos no sólo favorecieron la formación de todos los docentes que participaron, sino también permitieron hacer un primer rediseño de las PE compartidas. Las imágenes agrupadas en la Figura 5 muestran algunos momentos de dichos cursos.

\footnotetext{
${ }^{3} \mathrm{Si}$ bien este libro se encuentra aún en prensa algunas de las $\mathrm{PE}$ allí incluidas se han publicado en [40].
} 


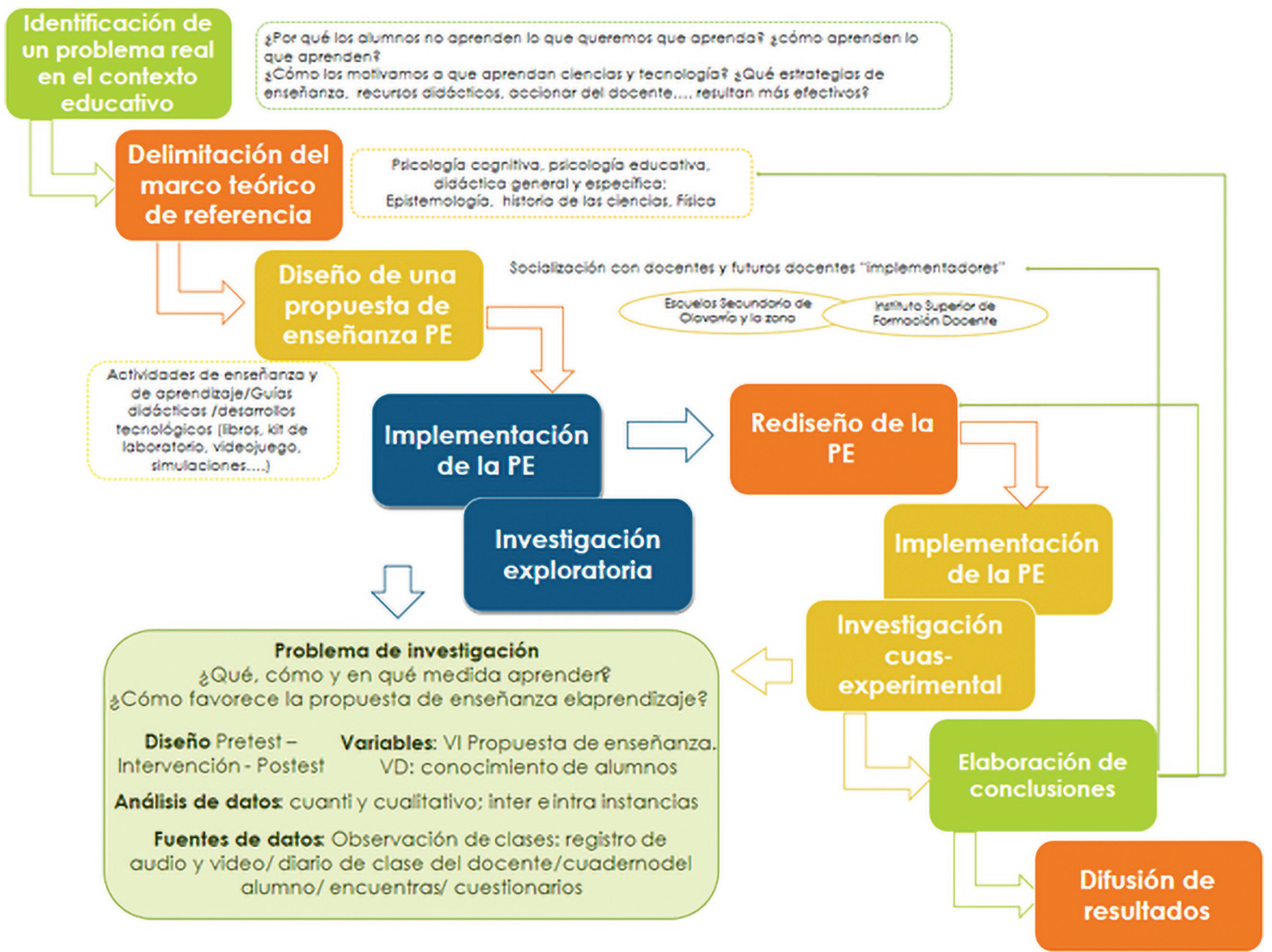

Figura 4: Fases de la Metodología IBD.
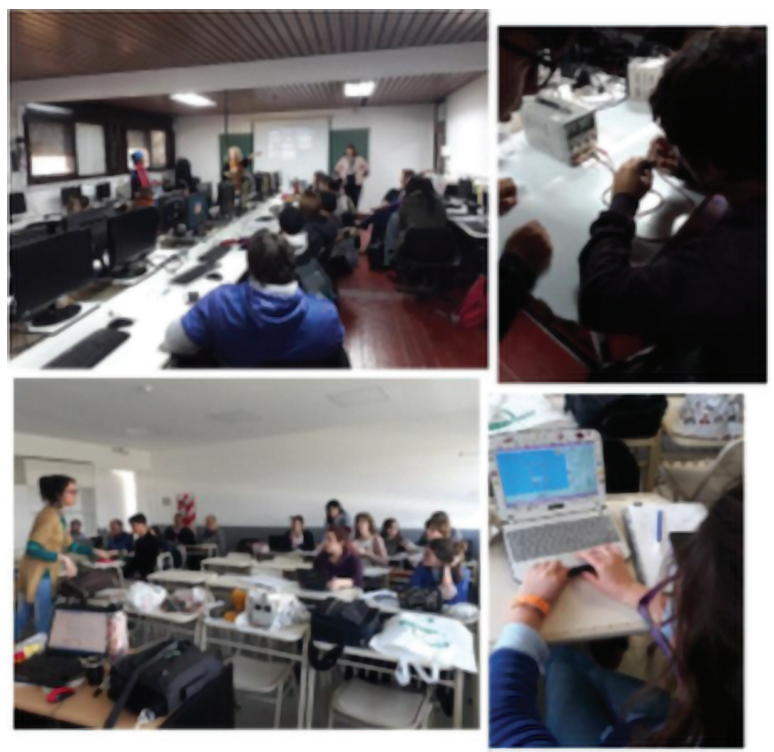

Figura 5: Imágenes de los cursos de capacitación docente.

\subsection{Sobre la implementación de las IDEAS}

Al momento se tiene registro de la implementación de las PE-IDAS en 10 escuelas de la ciudad de Olavarría, tanto de gestión pública como privada. La consolidación de un grupo interinstitucional (del que forman parte 5 docentes de educación secundaria) ha permitido realizar un seguimiento continuo de esas implementaciones y una evaluación continua que permite su periódico rediseño en post de convertirlas en herramientas cada vez más potentes para favorecer el objetivo central que persiguen: favorecer el aprendizaje de la física y el desarrollo de competencias digitales

La diversidad de contextos en las que han sido y están siendo aplicadas (incluido los virtuales a los que la pandemia por COVID 19 confinó a la educación durante el 2020) da indicios de la capacidad de adaptación/aplicación de los materiales diseñados a distintas situaciones, inquietudes, necesidades áulicas, contextos. Las imágenes agrupadas en la Figura 6 intentan dar cuenta de lo dicho.

Las evaluaciones cualitativas, que tanto de alumnos como docentes realizan al culminar las implementaciones es satisfactoria valorándose la motivación que éstas producen en los estudiantes y la ayuda que presenta a los docentes para organizar la enseñanza.

No obstante, y como se mencionó, se han realizado algunos estudios de casos para evaluar, con rigurosidad metodológica, el impacto de las PE-IDAS para favorecer el aprendizaje deseado. 


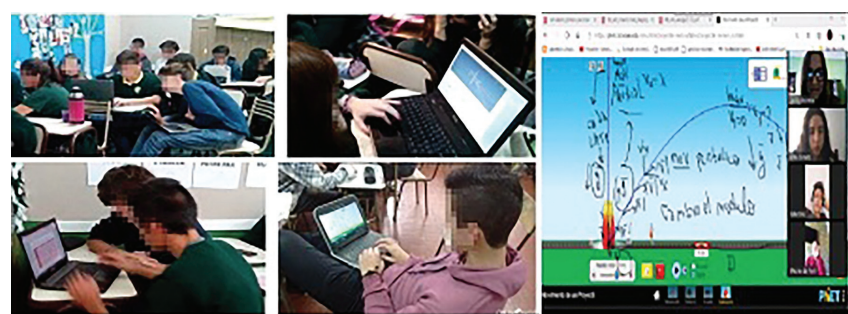

Figura 6: Imágenes de las implementaciones de las PE en distintos contextos.

\subsection{Sobre la potencialidad de las IDEA para favorecer los aprendizajes}

Si bien escapa a este trabajo la posibilidad de comentar ampliamente las investigaciones realizadas, vale mencionar que al momento se ha avanzado en el estudio del impacto de las PE-IDAS diseñadas para la enseñanza de temáticas relacionadas con la Óptica como son la visión directa de un objeto, la percepción de un color y la formación y visión de imágenes ópticas [3, 31, 42, 44].

Para ello se evaluó (a partir de estudios cuasi experimentales con diseño pretest - intervención - postest) cómo fue cambiando el modo de conocer que los estudiantes aplican para resolver problemas, antes durante y después de la enseñanza. Se trabajó con grupos completos de estudiantes de educación secundaria de edades comprendidas entre los 13 y 16 años.

En todos los casos hallamos que, antes de la implementación de la PE-IDAS los estudiantes tienden a utilizar modos de conocer intuitivos que pueden describirse en términos de principios ontológicos y conceptuales de hecho o dato y estado y de un realismo ingenuo. En tal sentido usan concepciones reduccionistas, mediante las cuales reconocen sólo algunas de las variables involucradas (ojos para la visión; objeto para el color lente para la formación de imágenes) desconociendo las interacciones que suceden entre ellas. Así por ejemplo tienden a explicar: "veo porque tengo ojos y miro", "el color es una propiedad de los objetos" "la lente es el elemento indispensable y suficiente para la formación de la imagen".

En tanto, una vez implementada la PE-IDAS se observó que los alumnos logran aplicar un conocimiento más coherente con el de la ciencia para explicar los fenómenos ópticos, reconociendo las variables involucradas (luz, sistema visual, objetos) y las interacciones que suceden entre ellas (reflexión, refracción). Así, por ejemplo, llegan a explicar que para ver "la luz reflejada difusamente por los objetos debe incidir en el sistema visual del observador" "que vemos un objeto rojo si luz roja llega a los ojos", "que una imagen óptica se forma como consecuencia de la interacción que sucede entre la luz emitida o reflejada difusamente por los objetos y la lente/espejo". Es decir que al final de la enseñanza los estudiantes tienden a usar un conocimiento complejo caracterizado por principios de sistema e interacción y modos de razonar multivariados, sistémicos.
Pero los resultados hallados también permitieron observar que durante ese aprendizaje no se produce una sustitución de las ideas intuitivas, ya que se detecta que las mismas siguieron siendo utilizadas en los distintos momentos de la enseñanza. Y si bien la probabilidad de uso fue cada vez menor conforme la enseñanza avanzó, este hecho deja de manifiesto que durante el aprendizaje no se "abandonan" las ideas más intuitivas lo que respalda la hipótesis de que el aprendizaje no sólo implica la construcción de los modelos propuestos por la ciencia sino también al desarrollo de la habilidad de gestionarlos y aplicarlos con consistencia.

Respecto de la potencialidad de las PE-IDAS, los datos hallados revelan que la metodología de diseñada resulta potencialmente útil para ayudar a los estudiantes a construir un saber coherente con el que propone la ciencia para explicar los fenómenos ópticos. Desde esta perspectiva, podemos concluir que favorecería eficazmente dicho aprendizaje el haber otorgado a los alumnos momentos especialmente diseñados para explicitar sus concepciones (en un intento de que sean consciente de lo que piensan y cómo piensan); participar de forma activa en el reconocimiento y construcción del saber de la ciencia (siguiendo la secuencia: identificación del fenómeno, identificación de las variables/elementos que intervienen, identificación de interacciones entre ellos; búsqueda de regularidades en los comportamientos observados, conclusión sobre el conceptos o ley involucrado); aplicar sus conocimientos en múltiples contextos y reflexionar sobre qué y cómo han aprendido.

A su vez, respecto del rol del docente podemos concluir (en base a lo hallado en [22, 24, 32]) que favorece el aprendizaje el hecho de que éste se comporte como guía, mediador y articulador de entornos y experiencias de aprendizaje, ayudando a los alumnos a resolver los problemas planteados, a clarificar sus modos de conocer, motivando las discusiones entre pares, promoviendo el espíritu crítico, despertando el interés para aprender y explicar múltiples fenómenos, estimulándolos a cuestionarse, a emitir predicciones, ayudándolos a contrastarlas, mostrándoles explícitamente la importancia de sus ideas pero también el poder explicativo de las ciencias, mostrándose ante ellos consciente de la complejidad que implica aprender ciencias pero también de la importancia que este proceso tiene para aprender a pensar diferente, para poder argumentar con consistencia y coherencia, para poder interpretar situaciones que antes no podían. También habría favorecido el aprendizaje el hecho de que el sintetizare/presentara/expusiera los conceptos y leyes analizados a partir de lo conocimiento que los propios alumnos explicitaban (tanto intuitivo como el que fueron construyendo al resolver las actividades propuestas) los guiara, explícita e intencionalmente, en el uso de esos nuevos saberes para la elaboración y resolución de problemas de aplicación propuesta y en la evaluación de qué fueron aprendido y qué falta por aprender. 
En síntesis, los resultados hallados son alentadores en tanto no sólo consolidan el marco teórico de referencia sobre qué significa aprender ciencias, sino que evidencian que las PE-IDAS favorece el aprendizaje deseado; aprendizaje que va más allá de la interpretación y comprensión de conceptos, leyes, modelos, teorías. . . ya que involucra el desarrollo de destrezas que hacen a una enculturación científica.

Como se discutió al comienzo de este trabajo, la sociedad actual demanda de ciudadanos alfabetizados científica y tecnológicamente, capaces de insertarse en la sociedad actual y actuar críticamente en ella, haciendo uso de saberes pertinentes y relevantes. Así, la función de la educación científica es favorecer no sólo la comprensión de leyes, modelos, teorías... sino también el desarrollo de habilidades relacionados con el uso consiente y consistente del saber construido. Un aprendizaje con estas características demanda de un alumno activo, partícipe consiente del aprendizaje que experimenta; un docente guía de este proceso y propuestas de enseñanza especialmente diseñadas para favorecer el aprendizaje.

Es cada vez mayor el consenso acerca de que la enseñanza tradicionalmente implementada en las aulas de Física, donde el docente se comporta como experto expositor y los estudiantes como pasivos receptores, no favorecen un aprendizaje como el deseado, sino que son necesarias metodologías activas, centradas en el estudiante y en la finalidad de su educación científica.

La metodología IDAS se enmarca dentro de estas metodologías más novedosas e innovadoras y los resultados de las investigaciones realizadas durante su implementación, dan cuenta de su potencialidad para contribuir al desarrollo de la ansiada alfabetización científica de los jóvenes estudiantes.

\section{Proyecciones}

Con el fin de hallar más datos que respalden la conclusión obtenida hasta aquí actualmente se está evaluando la potencialidad de la PE-IDAS para favorecer el aprendizaje de la conceptualización de fenómenos electromagnéticos (inducción electromagnética) tanto en nivel secundario como en nivel universitario. Si bien los resultados son incipientes los mismo parecen estar en consonancia respecto de los obtenidos al estudiar la enseñanza y el aprendizaje de la Óptica [34, 45, 46].

Por otra parte, y como se dijo, aprender ciencias va mucho más allá de conceptualizar el fenómeno. Por ello también se está incursionando respecto de cómo y en qué medidas las PE-IDAS implementadas favorecen el desarrollo de habilidades relacionadas con la resolución de problemas y uso crítico de las TIC.

Respecto del primero punto se ha empezado a estudiar qué estrategias ponen en juego los estudiantes de educación secundaria y universitaria al momento de resolver problemas abiertos de enunciado indefinido y qué obstáculos manifiestan tener que sortear para poder resolverlos [37] para, en función de ello, evaluar el posible rediseño de las PE-IDAS a fin de favorecer con mayor eficacia el desarrollo de habilidades deseado.

Respecto del segundo punto, al implementar la PEIDAS se observar que los alumnos se sienten interesados y motivados para interaccionar con las simulaciones y reconocen y valoran sus ventajas para optimizar su trabajo, haciéndolo más eficiente y ameno, y para entender más y mejor temáticas abordadas [47]. Pero se observó también que pese al uso cotidiano que los jóvenes dan a los dispositivos digitales, presentan dificultades al momento de editar y generar imágenes y videos, generar mapas conceptuales; incrustar imágenes en un procesador de texto, cargar datos en una planilla de cálculo y realizar gráficos a partir de los mismos [48]. A su vez, se observó que si pueden optar, eligen el formato tradicional de lápiz y papel para resolver las actividades y elaborar sus respuesta, ante que el procesador de textos o planillas de cálculos (esto daría indicios de que les resulta más cómodo usar aún el recurso físico tradicional con el que están más acostumbrados a trabajar, al menos en el contexto de la "escuela"). Pero cuando la tarea demanda explícitamente el uso de un recuro tecnológico, lograron usar sus teléfonos móviles y/o PC para acceder a la información propuesta en las actividades (mediante los códigos QR), elaborar los esquemas conceptuales, registrar los procedimientos experimentales (mediante fotografías y videos) o realizar una práctica virtual (a partir del uso de una simulación o laboratorio virtual). Lo dicho nos anima a pensar que las implementaciones de PE-IDAS logran convertir a las clases de Física en un espacio propicio no sólo para aprender el saber y saber hacer que subyace a esta disciplina sino también para aprender a usar recursos digitales.

No obstante, queda aún mucho por hacer como analizar el impacto que el uso de estas tecnologías ha tenido sobre el aprendizaje de la Física; el grado en que la inclusión de las TIC en clases de Física favorece la alfabetización digital; el grado en que la implementación longitudinal y sistemática de las PE-IDAS (abordando los contenidos curriculares establecidos para la educación secundaria) favorece la tan ansiada alfabetización científica. Seguimos trabajando en búsqueda de hallar datos concretos que nos permitan concluir al respecto.

\section{Agradecimientos}

Este trabajo fue posible gracias al apoyo de la Universidad Nacional del Centro de la Provincia de Buenos Aires, el CONICET y la Agencia Nacional de Promoción de la Investigación, el Desarrollo Tecnológico y la Innovación.

Agradecemos a todos los estudiantes y docentes que participaron, con gran compromiso y entusiasmo, de los diseños e implementaciones de las PE diseñadas, y, especialmente, a quienes conforman al equipo de IpACT 
Y agradecemos especialmente al colega Dr Leonardo Albuquerque Heidemann por la minuciosa lectura realizada a este trabajo, las pertinentes y oportunas sugerencias y cálidos comentarios efectuados.

\section{Referencias}

[1] Diseños Curriculares de Ciencias Naturales, Fisicoquímica, Física y Química para la Escuela Secundaria de la provincia de Buenos Aires, disponible en: http: //www.abc.gov.ar/ (2017).

[2] J. Guisasola, Ametller y K. Zuza, Revista Eureka sobre Enseñanza y Divulgación de las Ciencias 18, 1801 (2020).

[3] B. Bravo, La enseñanza y el aprendizaje de la visión y el color en educación secundaria. Tesis Doctoral. Universidad Autónoma de Madrid, Madrid (2008).

[4] J.I. Pozo, Humana mente. El mundo, la conciencia y la carne (Morata, Madrid, 2001).

[5] J.I. Pozo, Aprender en tiempos revueltos. La nueva ciencia del aprendizaje (Alianza Editorial, Madrid, 2016).

[6] S. Vosniadou, Human Development 50, 47 (2007).

[7] S. Vosniadou, Second International Handbook of Science Education 1, 119 (2012).

[8] M.T.H. Chi, Conceptual Change within and across Ontological Categories: Examples from Learning and Discovery in Science. En: Limón, M. y Mason, L (eds) Reconsidering Conceptual Change: Issues in Theory and Practice (Kluwer academic publishers, Londres, 2002).

[9] M.T.H. Chi, en Handbook of research on conceptual change, editado por S. Vosniadou (Erlbaum, New Jersey, 2008).

[10] M. Chi, R. Roscoe, J. Slotta, M. Roy y C. Chase, Cognitive Science 36, 1 (2012).

[11] L. Viennot, Razonar en física. La contribución del sentido común (A. Machado libros SA, Madrid, 2002).

[12] L. Viennot, en Physique, pour comprendre (Les Ulis: EDP Sciences, 2021).

[13] S. Islas y M. Pesa, Diferentes visiones acerca de los modelos científicos. Memorias del VI Simposio de Investigadores en Educación en Física (Corrientes, Argentina, 2002).

[14] A. Raviolo, P. Ramírez, E. López y A. Aguilar, Formación Universitaria 3, 29 (2010).

[15] P. Thagard, Conceptual Revolutions (Princeton, New Jersey, 1992).

[16] R. Hogarth, Educar la Intuición (Ediciones Paidós Ibérica, S.A. Barcelona y Editorial Paidós, SAICF, Buenos Aires, 2002).

[17] B. Bravo y M. Pesa, Gestión del conocimiento durante el aprendizaje de las ciencias. Un estudio de los procesos involucrados al aprender sobre la visión. Tercer Encuentro Nacional de Investigadores en desarrollo cognitivo y educación (Bariloche, Argentina, 2014).

[18] A. Karmiloff-Smith, Más allá de la modularidad (Alianza Editorial, Madrid, 1992).

[19] M. Montero, M. Braunmüller y B. Bravo, La resolución de problemas en carreras de ingeniería: capacidades y obstáculos de los estudiantes. Memorias VII Jornadas Nacionales y III Latinoamericanas de Ingreso y Permanencia en las Carreras Científico-Tecnológicas (2021), disponible en: https://ria.utn.edu.ar/xmlui/han dle $/ 20.500 .12272 / 5265$

[20] G. Polya, Cómo plantear y resolver problemas (Trillas, México, 1987).

[21] J. Pozo y C. Monereo, en Psicología del aprendizaje universitario: la formación de competencias, editado por J. Pozo y M. Pérez Echeverría (Coords.) (Morata, Madrid, 2009).

[22] J. Pozo y M. Pérez Echeverría, en Psicología del aprendizaje universitario: la formación de competencias, editado por J. Pozo y M. Pérez Echeverría (Coords.) (Morata, Madrid, 2009).

[23] J. Echeverría, Revista Iberoamericana de CTS. 10, 171 (2008).

[24] P. Lévy, Cibercultura Informe al Consejo de Europa (Anthropos Editorial, Barcelona, 2007).

[25] A. Jimoyiannis y V. Komis, Journal of Computers \& Education 36, 183 (2001).

[26] A. Pontes Pedrajas, Revista Eureka sobre Enseñanza y Divulgación de las Ciencias 2, 2 (2005).

[27] A. Rute y J. Leal, Revista de investigación y experiencias didácticas 31, 177 (2013).

[28] B. Bravo, M.J. Boucíguez y M. Braunmüller, Revista Eureka sobre Enseñanza y Divulgación de las Ciencias 16, 1203 (2019).

[29] B. Bravo, La Física y las Tic: la dupla del siglo. La energía (Editorial Unicen., Tandil, 2020).

[30] B. Bravo y M.J. Boucíguez, Alambique: Didáctica de las ciencias experimentales 91, 12 (2018).

[31] B. Bravo y M. Pesa, Revista Electrónica de Enseñanza de las Ciencias 15, 258 (2016).

[32] B. Bravo, A. Rocha y L. Eguren, Revista Electrónica de Enseñanza de las Ciencias 9, 283 (2014).

[33] A. Juárez y B. Bravo, Revista Iberoamericana de Educación 69, 97 (2015).

[34] M. Braunmüller, M. Juárez y B. Bravo, VII Jornadas nacionales y III latinoamericanas de ingreso y permanencia en carreras científico-tecnológicas - Libro de actas, disponible en: https://ria.utn.edu.ar/xmlui/handle/20 $.500 .12272 / 5265$, (2021).

[35] M. Truyol y Z. Gangoso, Investigações em Ensino de Ciências 5, 463 (2010).

[36] V. Oliveira, I.S. Araujo y E.A. Veit, Revista Brasileira de Ensino de Física 39, e3402 (2017).

[37] M. Montero, J. Inorreta y B. Bravo, Revista Enseñanza de la Física 32, 271 (2020).

[38] M. Molina, E. Castro, J. Molina y E. Castro, Enseñanza de las ciencias 29, 075 (2011).

[39] M.C. Rinaudo y D. Donolo, Revista de Educación a Distancia (RED) 22, 1 (2010).

[40] M.J. Bouciguez, B. Bravo, G. Santos y M. Abasolo, Congreso argentino de ingeniería (CADI) - IX congreso argentino de enseñanza de la ingeniería (CAEDI), (Chaco, 2016).

[41] M.J. Bouciguez, B. Bravo, G. Santos y M. Abasolo, Libro CIEDU 3, 422 (2019)

[42] B. Bravo, M. Pesa y J.L. Pozo, Investigações em Ensino de Ciências 14, 2, 299 (2009).

[43] B. Bravo, M. Pesa y J.L. Pozo, Enseñanza de las Ciencias 30, 87 (2012). 
[44] B. Bravo, M. Pesa y A. Rocha, Revista Electronica de Investigacion en Educacion en Ciencias, 8, 62 (2013).

[45] M. Braunmüller, B. Bravo y A. Juárez, Enseñanza de la Física, 31, 97 (2019).

[46] I. Inorreta, B. Bravo y S. Bravo, XXI Reunión de Educadores de Física (Argentina, 2021).

[47] B. Bravo, M.J. Boucíguez y A.M. Juárez, IV Jornadas de Enseñanza e Investigación Educativa en el campo de las Ciencias Exactas y Naturales (Universidad Nacional de La Plata, 2015).

[48] M. Braunmüller, B. Bravo y M.J. Boucíguez, Revista Eureka sobre Enseñanza y Divulgación de las Ciencias 16, 1203 (2019). 